\title{
Anti-inflammatory effects of Viola yedoensis and the application of cell extraction methods for investigating bioactive constituents in macrophages
}

\author{
Yun Hee Jeong ${ }^{1,2}$, You-Chang Oh ${ }^{1}$, Won-Kyung Cho ${ }^{1}$, Hyeji Shin ${ }^{2}$, Ki Yong Lee ${ }^{2^{*}}$ and Jin Yeul Ma ${ }^{1 *}$
}

\begin{abstract}
Background: Viola yedoensis (VY, Violaceae) is a popular medicinal herb used in traditional eastern medicine for treating lots of diseases, including inflammation and its related symptoms. However, the anti-inflammatory properties of VY have not been demonstrated. In the present study, we investigated the anti-inflammatory effects of VY ethanol extract (VYE) on macrophages and attempted to identify the bioactive components of VYE.

Methods: We assessed the effects of VYE on secretion of nitric oxide (NO) and inflammatory cytokines such as tumor necrosis factor (TNF)- $a$, interleukin (IL)-6, and IL-1 $\beta$. In addition, we explored the expression of inducible nitric oxide synthase (iNOS), cyclooxygenase (COX)-2, and changes in heme oxygenase (HO)-1, nuclear factor (NF)-kB, and mitogen-activated protein kinase (MAPK) signaling pathways in RAW 264.7 macrophages stimulated by lipopolysaccharide (LPS). In addition, a rapid and useful approach to identify potential bioactive components in VYE with anti-inflammatory effects was developed using murine macrophage cell extraction coupled with high-performance liquid chromatography tandem mass spectrometry (LC-MS).
\end{abstract}

Results: We found that VYE exerted anti-inflammatory activity by inhibiting the production of key inflammation mediators and related products, as well as suppression of HO-1, NF-kB, and MAPK signaling pathway activation in RAW 264.7 cells. In addition, we identified two compounds in VYE via the cell extraction method.

Conclusions: Our results revealed that VYE exerts anti-inflammatory activities and its detailed inhibitory mechanism in macrophages. Furthermore, we identified bioactive components of VYE.

Keywords: Viola yedoensis ethanol extract, Nuclear factor-kappaB, Mitogen-activated protein kinase, Heme oxygenase-1, Cell extraction, Bio-active components

\section{Background}

$\mathrm{VY}$ is one of the traditional medicinal herb that belongs to the violet family of Violaceae, called "Hojebigot" in Korea. The dried aerial component of VY is Viola Herba, and is produced in the southern regions of Korea, China, and Japan. VY is a well-known herb in traditional oriental medicine used for the treatment of inflammation-related diseases including swelling, sores, boils, furuncles,

\footnotetext{
* Correspondence: kylee11@korea.ac.kr; jyma@kiom.re.kr

${ }^{2}$ College of Pharmacy, Korea University, 2511, Sejongro, Sejong 30019, Republic of Korea

${ }^{1}$ Korean Medicine (KM)-Application Center, Korea Institute of Oriental

Medicine, 70, Cheomdanro, Dong-gu, Daegu 41062, Republic of Korea
}

carbuncles, snakebites, and acute and chronic hepatitis [1]. Recent studies have shown that VY has biological activities and pharmacological functions such as anti-HIV, anti-coagulant activities, and protective effects against LPS-induced acute lung injury in mice [2-4]. However, the detailed molecular mechanism of the antiinflammatory effects of VY is not well-characterized.

Inflammation is a first host immune response to protect the body from injury or infection. Normal inflammatory reactions are self-limited by down regulating proinflammatory proteins and increasing anti-inflammatory mediators $[5,6]$. The onset of chronic diseases-such as inflammatory arthritis, vascular diseases, and cancer-is 
closely associated with uncontrolled inflammatory responses or overproduction of inflammatory mediators [7].

Macrophages play a crucial role during inflammation by regulating immune responses. Macrophages activated by various stimulants can generate a broad array of proinflammatory mediators, such as NO, iNOS, COX-2, TNF- $\alpha$, IL-6, and IL-1 $\beta$ [8-10]. Inflammatory cytokine production and release in response to LPS is mediated by the activation of NF-kB and MAPK in macrophages $[11,12]$. NF-kB and MAPKs are typical inflammatory signaling pathways in macrophages. These two pathways induce pro-inflammatory cytokines and release a wide range of inflammatory mediators. Therefore, the majority of targets for the development of therapeutic approaches to treat various inflammatory diseases are associated with inhibition of these pathways.

In an unstimulated state, p65 of NF-kB is sequestered by inhibitors of NF-kB alpha $(\mathrm{IkB} \alpha)$ in the cytoplasm. Activation of NF-kB by inflammatory stimulants, such as LPS, occurs via phosphorylation and degradation of $\mathrm{IkB} \alpha$. Phosphorylated $\mathrm{IkB} \alpha$ is dissociated from the $\mathrm{p} 65 /$ $\mathrm{IkB} \alpha$ complex and free NF-kB translocates into the nucleus [13], where it regulates several genes important for immunity, including iNOS, COX-2, and certain cytokines [14-16]. MAPK consists of extracellular signalregulated kinase (ERK), Jun $\mathrm{NH}_{2}$-terminal kinase (JNK), and $\mathrm{p} 38$. MAPKs play a critical role in delivering inflammatory signals from the extracellular region to the intracellular region or nucleus [17]. MAPK is activated by phosphorylation of its component pathways to thereafter activate the NF-kB pathway and iNOS gene expression.

$\mathrm{NO}$ is synthesized from L-arginine by iNOS, whose expression is closely associated with the induction of HO-1. HO-1 is also one of the important regulator of inflammation and has exhibited an essential role in protecting the body from inflammatory processes [18]. Upon activated macrophages, $\mathrm{HO}-1$ and carbon monoxide $(\mathrm{CO})$ have been revealed to exert anti-inflammatory effects through decrease the expression of pro-inflammatory mediators including $\mathrm{NO}, \mathrm{PGE}_{2}$ and cytokines [19, 20]. Thus, enhanced the production of HO-1 expression may result in increased a lot of therapeutic agents.

To screening a bioactive components in a conventional procedures, it have been performed through a complex process, including isolating and purification of ingredient from natural products. Modern pharmacological researches have been investigated the potential biological activity of natural resources using the several new techniques, such as cell membrane chromatography, biomembrane affinity chromatography and cell extraction coupled with analytical techniques. We proposed a method of cell extraction coupled with LC-MS analysis to screen for bioactive components using macrophages. These techniques involve direct treatment of the natural products in the cells, incubation for $24 \mathrm{~h}$ to allow the bioactive components to selectively combine with specific receptors and/or channels and/or enzymes on the cell membrane or inside cells, extraction with $70 \%$ acetonitrile, and detection of the cell-combining components by LC-MS analysis. Recently, these methods were employed for screening of single compounds or drug candidates from natural resources used in traditional medicine [21, 22].

In present study, we examined the anti-inflammatory effects of VYE on LPS-induced inflammation in RAW 264.7 and mouse primary macrophage cells. In addition, we evaluated whether VYE regulates NF-kB, MAPK, and HO-1 pathways to demonstrate its inhibitory mechanism underlying its anti-inflammatory effect. Furthermore, we explored the bioactive components of VYE using cell extraction.

\section{Methods \\ Preparation of VYE}

VY was obtained as a dried herb from Yeongcheonhyundai Herbal Market (Yeongcheon, Korea) and verificated by Prof. KiHwan Bae (Chungnam National University, Daejeon, Korea). The voucher specimen of VY was stored in the herbarium of KM-Application Center, Korea Institute of Oriental Medicine. The pulverized plant $(30.0 \mathrm{~g})$ was extracted with $390 \mathrm{~mL}$ of $70 \%$ ethanol at $40{ }^{\circ} \mathrm{C}$ in a shaking incubator $(100 \mathrm{rpm})$ for $24 \mathrm{~h}$. After extraction, the solution was filtered using 185mm filter paper (Whatman, Piscataway, NJ, USA) and enrichmented using a rotary vacuum evaporator (Buchi, Tokyo, Japan). Samples were then freeze-dried and maintained in desiccators at $-20{ }^{\circ} \mathrm{C}$ before use. The yield of VYE was $11.25 \%$.

\section{Materials and reagents}

Roswell Park Memorial Institute (RPMI) 1640 medium, antibiotics, and fetal bovine serum (FBS) were obtained from Hyclone (Logan, UT, USA). All cell culture dishes and plates were obtained from SPL life sciences (Pocheon, Korea). LPS, dexamethasone, bovine serum albumin (BSA), cell counting kit (CCK), and enzyme-linked immunosorbent assay (ELISA) antibody sets were obtained from Sigma (St. Louis, MO, USA), Dojindo (Kumamoto, Japan), and eBioscience (San diego, CA, USA), respectively. Various primary antibodies for Western blot analysis were purchased from Cell Signaling Technology (Boston, MA, USA). Horseradish peroxidase (HRP)-conjugated secondary antibodies were obtained from Thermo Scientific (Rockford, IL, USA). An extraction kit for RNA isolation was purchased from iNtRON (Sungnam, Korea). DNA synthesis kits, oligonucleotide primers, and AccuPower $^{\oplus}$ 2X Greenstar qPCR Master Mix (ROX) were obtained from Bioneer (Daejeon, Korea). 


\section{Macrophage cell culture and treatment of test drug}

The murine macrophage RAW 264.7 was obtained from the American Type Culture Collection (ATCC, Manassas, VA, USA) and maintained in RPMI 1640 (contained $10 \%$ FBS and antibiotics). Cells were then incubated in humidified $5 \% \mathrm{CO}_{2}$ atmosphere at $37{ }^{\circ} \mathrm{C}$. To stimulate the inflammatory signals of macrophages, the RPMI 1640 medium was exchanged for fresh medium and $200 \mathrm{ng} / \mathrm{mL}$ of LPS was added in the presence or absence of VYE (10, 30, 50, 100 and $150 \mu \mathrm{g} / \mathrm{mL}$ ) for the indicated periods.

\section{Isolation of mouse peritoneal macrophage and cell culture}

Male BALB/c mice $(25 \pm 3 \mathrm{~g})$ were obtained from SamtakoBioKorea (Osan, Korea). $300 \mu \mathrm{L}$ of sterilized $3 \%$ sodium thioglycollate (Sigma, St. Louis, MO, USA) was injected to abdominal cavity of mice. All mice were housed at 5 per cage at room temperature (RT) under a 12-h: 12-h light/dark cycle. After three days, the mice were killed and peritoneal macrophages were collected by washing peritoneal cavity with $10 \mathrm{~mL}$ (per each mouse) of ice-cold phosphate-buffered saline (PBS). The cells were centrifuged at $2000 \mathrm{rpm}$ for $5 \mathrm{~min}$ at $4{ }^{\circ} \mathrm{C}$ and the supernatant containing red blood cell (RBC) debris was discarded. The cell pellet was resuspended in completed RPMI 1640 and incubated for $18 \mathrm{~h}$ for attachment to the culture plate [23]. To stimulate the cells, the medium was exchanged for fresh RPMI 1640 and LPS was added in the presence or absence of VYE for $24 \mathrm{~h}$. Animal study was performed according to the Guide for the Animal Care and Use Committee of the Korea Institute of Oriental Medicine (reference numbers: 14-079).

\section{Cell viability assays}

RAW 264.7 macrophages were mechanically scraped and plated into 96 well culture plates $\left(5 \times 10^{4}\right.$ cells/well $)$. After $18 \mathrm{~h}$, five concentrations of VYE were added to the cells and incubated for $24 \mathrm{~h}$. CCK solutions $(10 \mu \mathrm{L})$ were applied to each well. Then the cells were incubated for a further $1 \mathrm{~h}$. The optical density value was readed at $450 \mathrm{~nm}$ using an ELISA reader (infinite M200, Tecan, Männedorf, Switzerland).

\section{Measurement of NO production}

To measure secretion of $\mathrm{NO}$, cells were plated into 96 well culture plates $\left(5 \times 10^{4}\right.$ cells/well). After $18 \mathrm{~h}$, cells were treated with VYE and stimulated using LPS for 24 h. Griess reagent ( $1 \%$ sulfanilamide, $0.1 \% \mathrm{~N}-1$ napthylethylenediamine dihydrochloride, and $2.5 \%$ phosphoric acid) was added to each well and further incubated at RT for $5 \mathrm{~min}$ [24]. Absorbance at $570 \mathrm{~nm}$ was determined using the ELISA reader.

\section{Determination of inflammatory cytokines}

To explore the inhibitory effects of VYE on cytokine production in macrophages upon LPS stimulation, the secretion of TNF- $\alpha$, IL- 6 , and IL- $1 \beta$ was measured using an ELISA antibody set. Macrophages were grown in 24 well culture plates $\left(5 \times 10^{4}\right.$ cells/well). The cells were pretreated with VYE for $1 \mathrm{~h}$ and then challenged with LPS for another $24 \mathrm{~h}$. The supernatants were then centrifuged at $13000 \mathrm{rpm}$ at $4{ }^{\circ} \mathrm{C}$ for 5 min for discarded cell debris. The levels of cytokine were analyzed using ELISA antibody sets, according to protocol of manufacturer.

\section{Preparation of whole cell, cytoplasmic and nuclear fractions}

To measure protein expression, cells were stimulated by LPS treatment in the presence or absence of VYE for the indicated periods $(30 \mathrm{~min}-24 \mathrm{~h}$ ). After incubation with VYE and/or LPS, cells were collected and resuspended in radio immunoprecipitation assay (RIPA) buffer (Millipore, Bedford, MA, USA) containing inhibitor cocktail (protease and phosphatase inhibitor) to get whole cell lysates. Cytoplasmic and nuclear lysates were isolated by NE-PER nuclear and cytoplasmic extraction reagents (Thermo Scientific, Rockford, IL, USA) according to protocol of manufacturer.

\section{Western blot analysis}

Total proteins of whole cell lysates or cytoplasmic and nuclear extracts were assayed using Bradford's reagent (Bio-Rad Hercules, CA, USA). The proteins were divided using sodium dodecyl sulfate-polyacrylamide gel electrophoresis (SDS-PAGE) and transferred to a nitrocellulose

Table 1 Primers used for real-time RT-PCR analysis

\begin{tabular}{|c|c|}
\hline Target gene & Primer sequence \\
\hline \multirow[t]{2}{*}{ TNF-a } & F: 5'-TTCTGTCTACTGAACTTCGGGGTGATCGGTCC-3' \\
\hline & R: 5'-GTATGAGATAGCAAATCGGCTGACGGTGTGGG-3' \\
\hline \multirow[t]{2}{*}{ IL-6 } & F: 5'-TCCAGTTGCCTTCTTGGGAC-3' \\
\hline & R: 5'-GTGTAATTAAGCCTCCGACTTG-3' \\
\hline \multirow[t]{2}{*}{$\| L-1 \beta$} & F: 5'-ATGGCAACTGTTCCTGAACTCAACT-3' \\
\hline & R: 5'-CAGGACAGGTATAGATTCTTCCTाT-3' \\
\hline \multirow[t]{2}{*}{ iNOS } & F: 5'-GGCAGCCTGTGAGACCTITG-3' \\
\hline & R: 5'-GCATTGGAAGTGAAGCGTTTC-3' \\
\hline \multirow[t]{2}{*}{$\operatorname{cox}-2$} & F: 5'-TGAGTACCGCAAACGCTTCTC-3' \\
\hline & R: 5'-TGGACGAGGTIITCCACCAG-3' \\
\hline \multirow[t]{2}{*}{$\mathrm{HO}-1$} & F: 5'-TGAAGGAGGCCACCAAGGAGG-3' \\
\hline & R: 5'-AGAGGTCACCCAGGTAGCGGG-3' \\
\hline \multirow[t]{2}{*}{$\beta$-actin } & F: 5'-AGAGGGAAATCGTGCGTGAC-3' \\
\hline & R: 5'-CAATAGTGATGACCTGGCCGT-3' \\
\hline
\end{tabular}

$F$ forward, $R$ reverse 


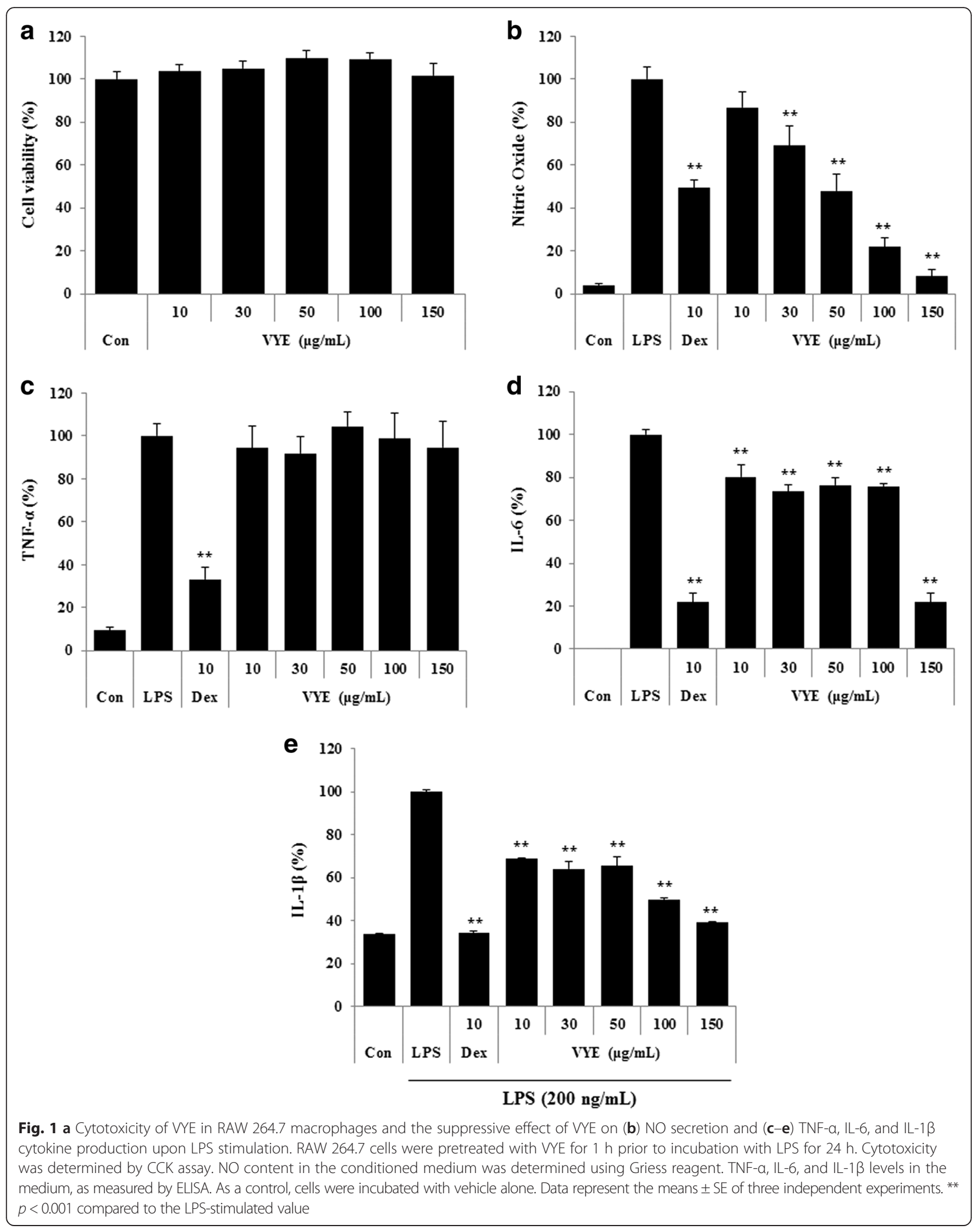


(NC) membrane (Millipore, Bedford, MA, USA). After blocking of nonspecific sites with $3 \%$ BSA, the membranes were incubated with each primary antibodies at RT $2 \mathrm{~h}$ or $4{ }^{\circ} \mathrm{C}$ overnight. The membranes were subsequently incubated with HRP-conjugated anti-mouse or anti-rabbit secondary antibodies. The signals were detected using Super Signal West Femto chemiluminescent substrate (Thermo Scientific, Rockford, IL, USA).

Total RNA extraction and real-time reverse transcriptionpolymerase chain reaction (real-time RT-PCR)

Total cellular RNA was extracted by easy-BLUE ${ }^{\mathrm{m} M}$ RNA extraction kit (iNtRON Biotech, Daejeon, Korea) in accordance with the protocol of manufacturer. cDNA was synthesized from $1 \mu \mathrm{g}$ of total RNA using AccuPower ${ }^{\circ}$ CycleScript RT PreMix (Bioneer, Daejeon, Korea). The oligonucleotide primers for real-time RT-PCR are indicated in Table 1 [25]. The samples were setup in triplicate in a $20 \mu \mathrm{L}$ total volume: $0.3 \mu \mathrm{M}$ final concentrations of each primer $(1 \mu \mathrm{L}$ of forward and reverse primer), $10 \mu \mathrm{L}$ of AccuPower $2 \mathrm{X}$ Greenstar qPCR Master Mix (Bioneer, Daejeon, Korea), $3 \mu \mathrm{L}$ of $0.1 \%$ DEPCtreated water, and $5 \mu \mathrm{L}$ of template DNA. The following PCR conditions were applied: TNF- $\alpha$, IL-6, IL- $1 \beta$, iNOS, COX-2, HO- 1 , and $\beta$-actin, with 40 cycles of $94{ }^{\circ} \mathrm{C}$ for $15 \mathrm{~s}$ and $60{ }^{\circ} \mathrm{C}$ for $1 \mathrm{~min}$ [25]. The amplification and analysis were performed by a QuantStudio 6 Flex Real-time PCR System (Thermo Scientific, Rockford, IL, USA). Samples were compared by the relative CT method. The results of real-time RT-PCR were presented as inflammatory mediator gene induction fold, which were calculated using $\beta$-actin as an internal control.

\section{Cell extraction}

RAW 264.7 cells were seeded into $100-\mathrm{mm}$ culture dishes at a density of $1.0 \times 10^{6}$ cells $/ \mathrm{mL}$, grown in completed RPMI medium, and maintained at $37^{\circ} \mathrm{C}$ in an atmosphere of $5 \% \mathrm{CO}_{2}$ for $18 \mathrm{~h}$. The culture medium was discarded, and serum-free RPMI medium and VYE (at a final concentration of $150 \mu \mathrm{g} / \mathrm{mL}$ ) were added, followed by incubation for $24 \mathrm{~h}$. The cells were then harvested and centrifuged at $2000 \mathrm{rpm}$ for $5 \mathrm{~min}$, after which the deposited cells were washed five times with PBS to remove uncombined components. Finally, the deposited cells were extracted with $1 \mathrm{~mL}$ of $70 \%$ acetonitrile by ultrasonic extraction for $1 \mathrm{~h}$. After centrifugation at 13,000 rpm for $10 \mathrm{~min}$, the obtained supernatant was filtered through $0.45 \mu \mathrm{m}$ nylon membranes for LC-MS analysis.

\section{The application of HPLC coupled with Q-TOF mass spectrometry}

Agilent 1260 series (Agilent, Santa Clara, CA, USA) was used for chromatography analysis with an online degasser, a binary pump, an auto plate-sampler, a thermostatically

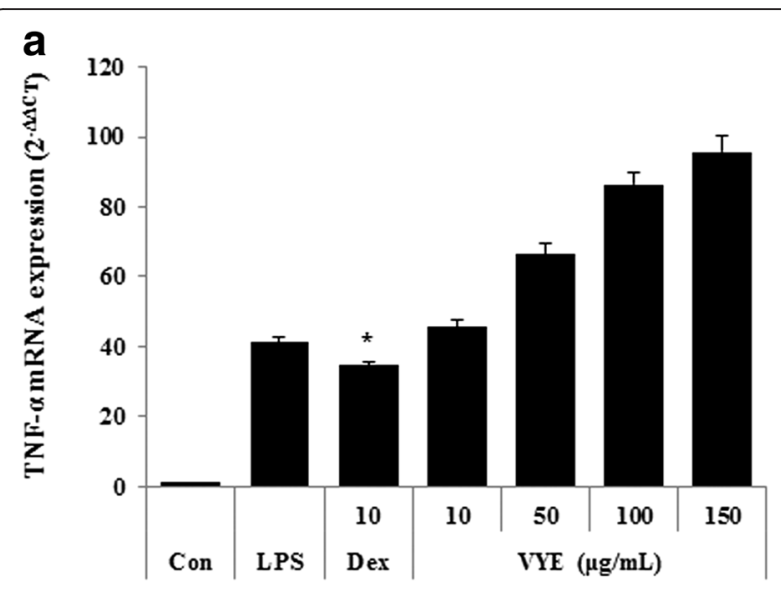

b
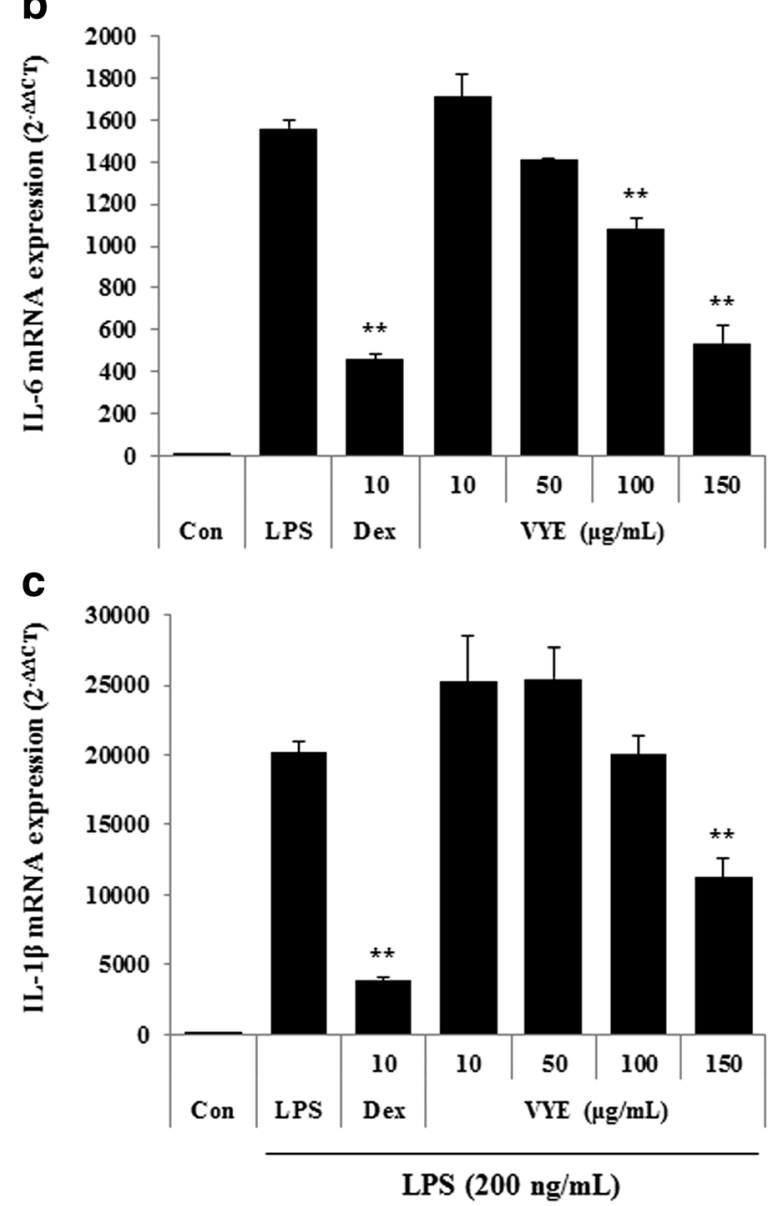

Fig. 2 Effect of WYE on LPS-induced (a) TNF- $a$, (b) IL-6, and (c) IL-1 $\beta$ mRNA expression in macrophages. Cells were pretreated with WE for $1 \mathrm{~h}$ and stimulated with LPS for a further $6 \mathrm{~h}$. mRNA levels were analyzed by real-time RT-PCR. Amplification and analyses of mRNA were performed using the QuantStudio 6 Flex Real-time PCR System (Thermo Scientific, Rockford, IL, USA). Data represent the means \pm SE of three independent experiments. ${ }^{*} p<0.01$ and ${ }^{* *} p<0.001$ compared to the LPS-stimulated value 
controlled column compartment, and a UV detector. Chromatographic separation was achieved on an Shiseido CapCell PAK C18 column $(150 \times 4.6 \mathrm{~mm}, 5 \mu \mathrm{m})$ by gradient elution of a mixture of water (solvent A) and acetonitrile (solvent B) containing $0.1 \%$ formic acid at a flow rate $0.6 \mathrm{~mL} / \mathrm{min}$. The gradient elution system was as below: 0-5 $\mathrm{min}, 15 \% \mathrm{~B}$; 5-30 $\mathrm{min}, 15-95 \% \mathrm{~B}$. A tandem quadrupole time-of-flight (Q-TOF) mass spectrometery was performed on an Agilent 6530 Q-TOF mass spectrometer (Agilent, Santa Clara, CA, USA). The acquisition parameters were set as follows. The analysis was operated in negative ion mode with an electrospray ionization (ESI) interface. The nebulizer pressure was set to 40 psi. The voltages of capillary, fragmentor, and skimmer were set to $4000 \mathrm{~V}, 175 \mathrm{~V}$, and $65 \mathrm{~V}$, respectively. The gas used for both drying and sheath was nitrogen. The temperature and flow rate of gas for each process were $325^{\circ} \mathrm{C}$; $10.0 \mathrm{~L} /$ $\min$ and $350{ }^{\circ} \mathrm{C} ; 12.0 \mathrm{~L} / \mathrm{min}$. The mass scan range was configured from 50 to $1000 \mathrm{~m} / z$ and all data were collected in centroid mode. The accurate-mass capability of the TOF analyzer allowed reliable confirmation of the identity of the detected metabolites, normally with mass errors below $5 \mathrm{ppm}$ in routine analysis. The MassHunter Workstation software LC/MS Data Acquisition for 6530 series Q-TOF (version B.05.00) was used to adjust the parameters for acquiring data.

\section{Extraction, fractionation and isolation}

Dried whole plants of VY (600.0 g) were ground and extracted three times with $70 \%$ ethanol for 90 min using

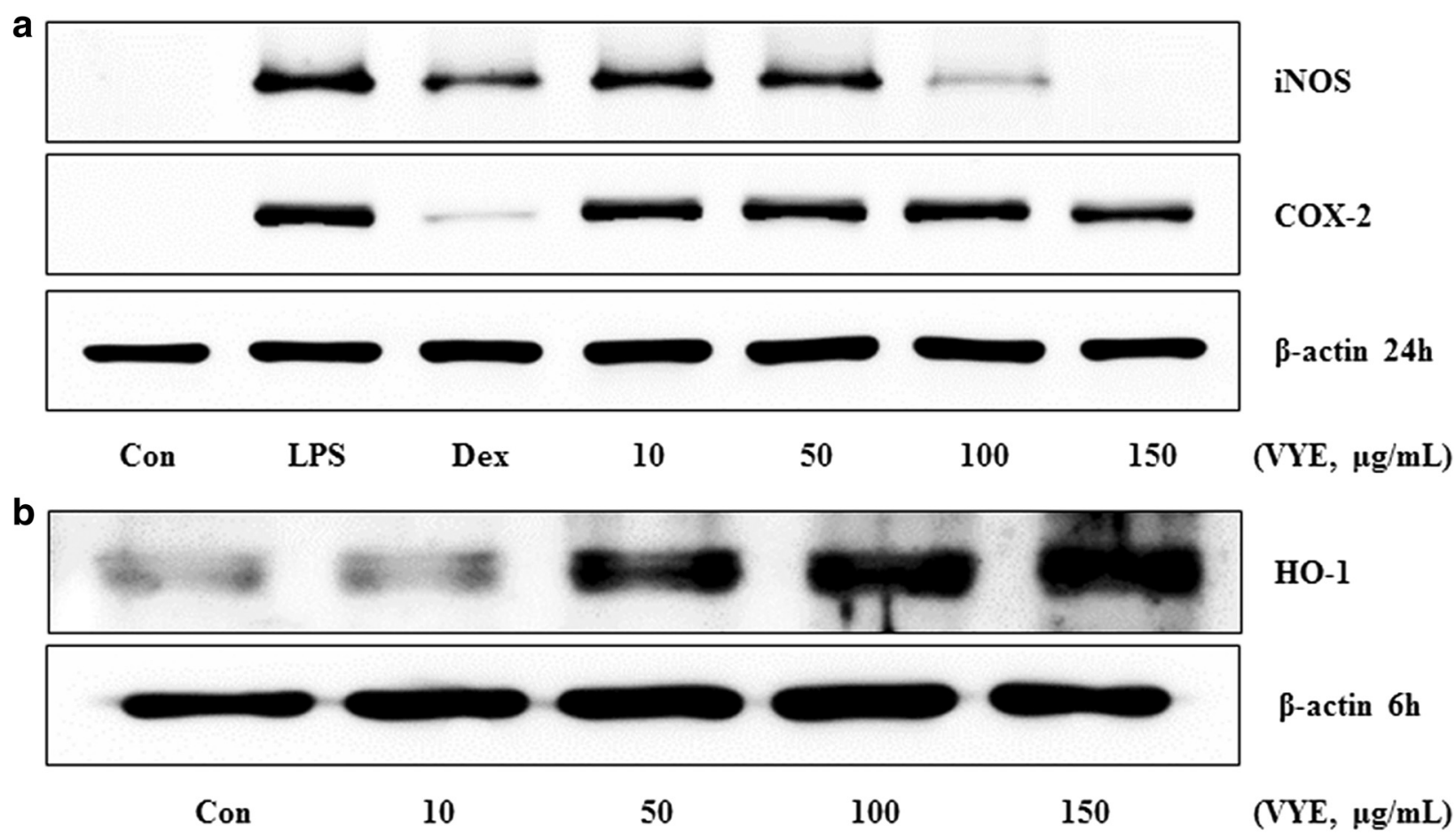

iNOS/B-actin

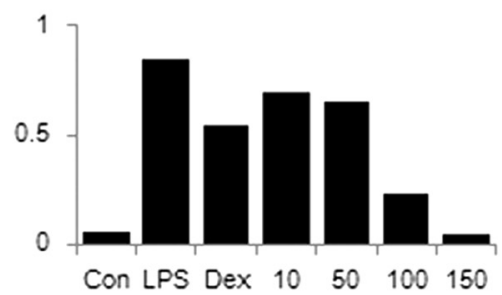

coX-2/3-actin

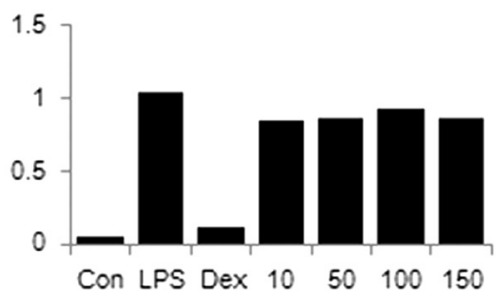

HO-1/ $\beta$-actin

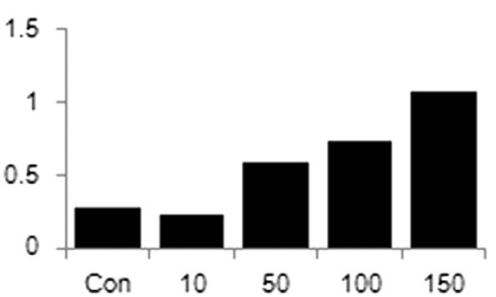

Fig. 3 Effect of WYE on (a) iNOS, COX-2 protein levels, and (b) HO-1 protein induction in RAW 264.7 cells. Cells were treated with (a) LPS alone or LPS plus VYE for $24 \mathrm{~h}$ or with (b) VYE alone for $6 \mathrm{~h}$. Protein levels were determined by Western blotting, as described in the Materials and Methods, and quantitated using a Davinch-chemi ${ }^{\mathrm{TM}}$ CAS-400SM chemiluminescence imaging system (Core Bio, Seoul, Korea). $\beta$-actin served as a control. The experiment was repeated three times independently, and similar results were obtained 
an ultrasonicator. The solvent was then evaporated under vacuum. The residue $(58.2 \mathrm{~g})$ was suspended in water and then partitioned with $n$-hexane, EtOAc, and $n$ - $\mathrm{BuOH}$, successively. The $n$ - $\mathrm{BuOH}$ fraction (16.5 g) was separated into six fractions (VY 2A-2 F) on an HP-20 column chromatography using gradient elution with $\mathrm{H}_{2} \mathrm{O}$ $100 \%$ to $\mathrm{MeOH} 100 \%$. According to the TLC profiles, fraction VY-2D was re-chromatographed on $\mathrm{RP} \mathrm{C}_{18}$ column chromatography using gradient elution with $\mathrm{H}_{2} \mathrm{O}-\mathrm{MeOH}$ (2:1 to 3:2) to give Compound 1 (273 mg) and Compound 2 (226 mg). A summary of the extraction, fractionation, and isolation scheme is shown in Fig. 9.

\section{Compound 1; Isoschaftoside}

ESI-MS $m / z 563.1441[\mathrm{M}-\mathrm{H}]^{-}$. ${ }^{1} \mathrm{H}-\mathrm{NMR}(600 \mathrm{MHz}$, DMSO- $\left.\mathrm{d}_{6}\right): \delta 8.03\left(2 \mathrm{H}, \mathrm{d}, \mathrm{J}=8.5 \mathrm{~Hz}, \mathrm{H}-2^{\prime}\right.$ and $\left.\mathrm{H}-6^{\prime}\right)$, $6.92\left(2 \mathrm{H}, \mathrm{d}, \mathrm{J}=8.5 \mathrm{~Hz}, \mathrm{H}-3^{\prime}\right.$ and $\left.\mathrm{H}-5^{\prime}\right), 6.82(1 \mathrm{H}, \mathrm{s}$, $\mathrm{H}-3), 4.76$ (1H, d, J = 9.5 Hz, Glc-H-1), 4.72 (1H, d, J = 9.8 Hz, Ara-H-1), 3.25-3.90 (9H, m, Ara-H-2-5 and GlcH-2-6) ppm. ${ }^{13} \mathrm{C}-\mathrm{NMR}\left(150 \mathrm{MHz}, \mathrm{DMSO}-\mathrm{d}_{6}\right): \delta 61.3$ (Glc-C-6), 68.5 (Ara-C-4), 69.6 (Ara-C-2), 70.2 (Ara-C5), 70.6 (Glc-C-4), 71.0 (Gla-C-2), 73.3 (Glc-C-1), 73.9 (Ara-C-3), 74.2 (Ara-C-1), 78.9 (Glc-C-3), 81.9 (Glc-C5), 102.6 (C-3), 103.7 (C-10), 105.8 (C-8), 108.1 (C-6), 116.0 (C-3' and C-5'), 121.2 (C-1'), 129.1 (C-2' and C-6'), 155.1 (C-9), 158.3 (C-5), 161.1 (C-7), 161.3 (C-4'), 164.1 (C-2), 182.4 (C-4) ppm.

\section{Compound 2; Apigenin 6, 8-di-C-a-L-arabinopyranoside}

$\mathrm{ESI}-\mathrm{MSm} / z \quad 533.1363 \quad[\mathrm{M}-\mathrm{H}]^{-}$. ${ }^{1} \mathrm{H}-\mathrm{NMR}(600 \mathrm{MHz}$, DMSO- $\left.\mathrm{d}_{6}\right): \delta 8.02\left(2 \mathrm{H}, \mathrm{d}, \mathrm{J}=8.4 \mathrm{~Hz}, \mathrm{H}-2^{\prime}\right.$ and $\left.\mathrm{H}-6^{\prime}\right)$, $6.91\left(2 \mathrm{H}, \mathrm{d}, \mathrm{J}=8.4 \mathrm{~Hz}, \mathrm{H}-3^{\prime}\right.$ and $\left.\mathrm{H}-5^{\prime}\right), 6.83(1 \mathrm{H}, \mathrm{s}, \mathrm{H}-$ 3), $4.70\left(1 \mathrm{H}, \mathrm{d}, \mathrm{J}=9.5 \mathrm{~Hz}\right.$, Ara- $\left.\mathrm{H}-1^{\prime}\right), 4.70(1 \mathrm{H}, \mathrm{d}, \mathrm{J}=$ 9.5 Hz, Ara-H-1"), 3.44-3.89 (10H, m, Ara-H-2' $-5^{\prime}$ and Ara-H-2" $-5 ")$ ppm. ${ }^{13} \mathrm{C}-\mathrm{NMR}\left(150 \mathrm{MHz}, \mathrm{DMSO}-\mathrm{d}_{6}\right): \delta$ 182.3 (C-4), 164.2 (C-2), 161.5 (C-7), 161.2 (C-5), 161.2 (C-4'), 155.0 (C-9), 129.5 (C-2' and C-6'), 121.1 (C-1'), \left.116.0 (C-3' and ${\mathrm{C}-5^{\prime}}^{\prime}\right), 108.3$ (C-6), 104.9 (C-8), 103.4 (C-10), 102.3 (C-3), 74.1 (Ara-C-1'), 74.1 (Ara-C-1"), 74.0 (Ara-C-3'), 74.0 (Ara-C-3"), 70.2 (Ara-C-5'), 70.2 (Ara-C-5"), 69.0 (Ara-C-2'), 69.0 (Ara-C-2"), 68.6 (AraC-4'), 68.6 (Ara-C-4'") ppm.

\section{Statistical analysis test}

All data are presented as means \pm SD of three independent experiments unless stated otherwise. Significant differences were determined using Student's t-tests after comparing each treated group to the LPS group. Each experiment was repeated three times or more to yield comparable results. Values of $* P<0.01$ and $* P<0.001$ were considered to indicate statistical significance.

\section{Statistical analysis software}

GraphPad Prism version 5.02 software (GraphPad Software, Inc., San Diego, CA) was used for all the statistical analyses in this study.
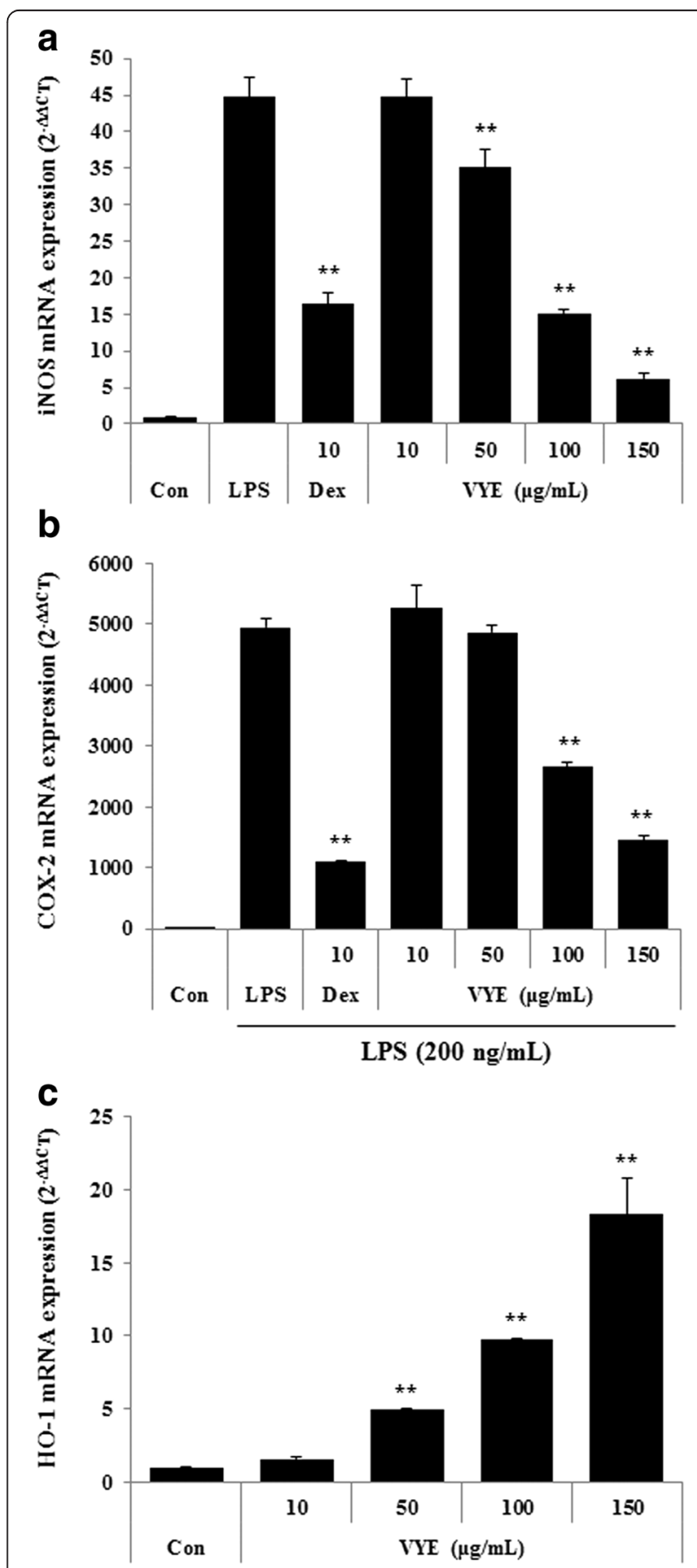

Fig. 4 Effects of VYE on mRNA expression of (a) iNOS, (b) COX-2, and (c) HO-1 in macrophages. Cells were treated with $(\mathbf{a}, \mathbf{b})$ LPS alone or with LPS and VYE for $24 \mathrm{~h}$ and (c) VYE alone for $3 \mathrm{~h}$. Data represent the means \pm SE of determinations from three independent experiments. ${ }^{* *} p<0.001$ compared to the LPS-stimulated value 


\section{Results}

Effect of VYE on cell viability and NO production in RAW 264.7 cells

To investigate the cytotoxicity of VYE in RAW 264.7 cells, we conducted viability assays using CCK. As shown in Fig. 1a, 10 and $150 \mu \mathrm{g} / \mathrm{mL}$ of VYE had no effect on RAW 264.7 cell viability. Thus, to exclude the potential influence of cytotoxicity, the concentration of VYE was limited to $150 \mu \mathrm{g} / \mathrm{mL}$ in subsequent experiments. Half maximal inhibitory concentration (IC50) value of VYE on the viability of RAW 264.7 cells was $278.8 \mu \mathrm{g} / \mathrm{mL}$ and IC50 of dexamethasone was $390.3 \mu \mathrm{M}$ (data not shown). Dexamethasone, which is widely used for the treatment of inflammation-related disease, was used as a positive control in this study. Because NO production is related with various inflammatory diseases, we measured the inhibitory activity of VYE on NO production in LPS-stimulated macrophages. The concentration of nitrite in supernatants was determined using Griess reagent. As shown in Fig. 1b, the release of NO was significantly inhibited by VYE pretreatment in a concentration-dependent manner. Especially, $150 \mu \mathrm{g} / \mathrm{mL}$ VYE inhibited NO production by more than $90 \%$.

Inhibitory activities of VYE on secretion of inflammatory cytokines and their mRNA expression

To further analyze the potential inhibitory activity of VYE on inflammatory cytokines (TNF-a, IL-6, and IL-1 $\beta$ ) production and their mRNAs expression, we used ELISA and real-time RT-PCR. As shown in Fig. 1c, d and e, secretion

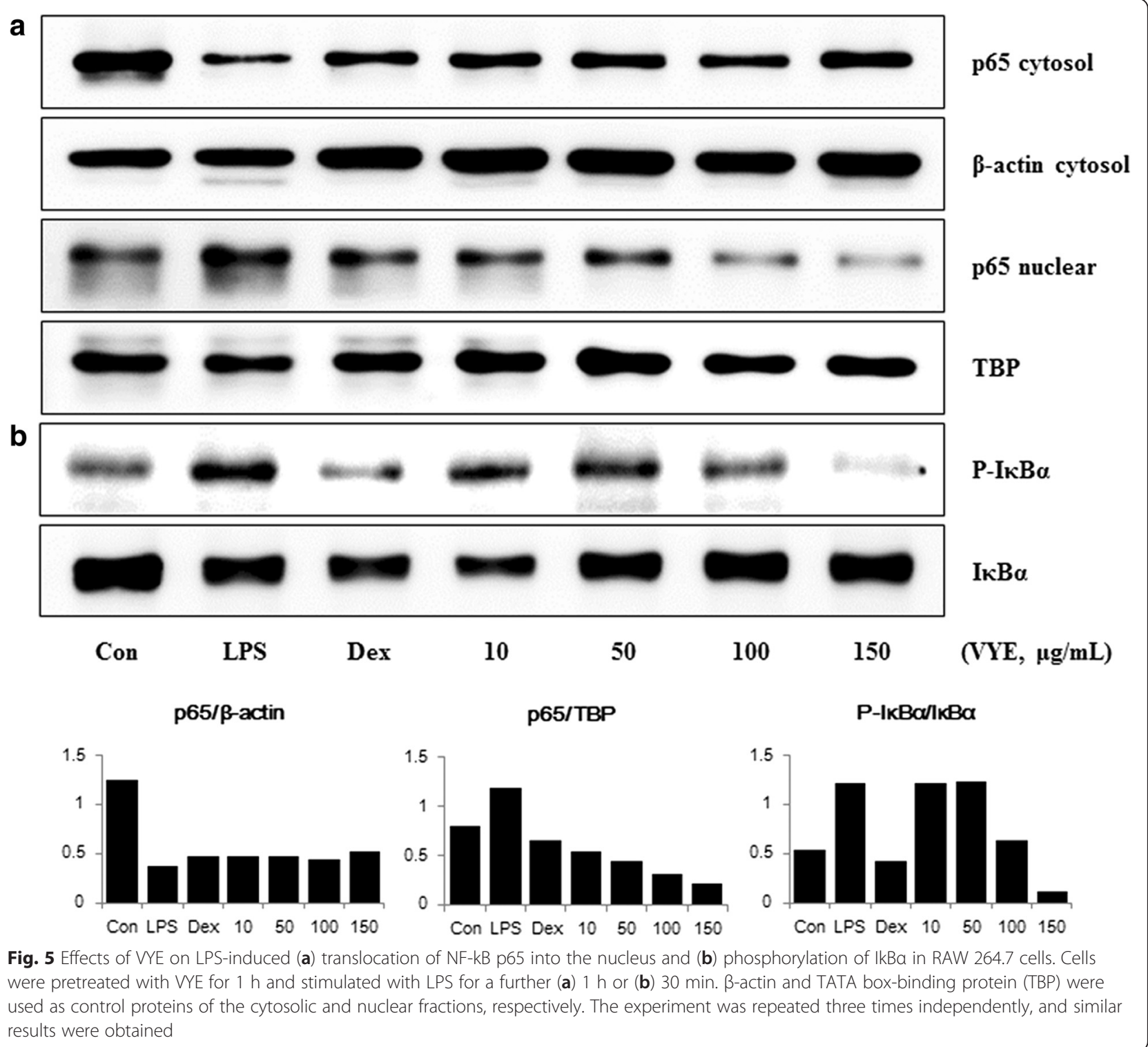


of IL- 6 and IL-1 $\beta$ was significantly repressed by VYE in a dose-dependently. However, VYE had no effect on TNF- $\alpha$ secretion compared with the negative control (LPS treated only) in this assay. Consistent with this result, expression of TNF- $\alpha$ mRNA was not inhibited by treatment with VYE at any concentration (Fig. 2a). However, VYE showed an inhibitory activity on IL- 6 and IL-1 $\beta$ mRNA expression at $100 \mu \mathrm{g} / \mathrm{mL}$ or higher (Fig. $2 \mathrm{~b}$ and c).

VYE strongly represses iNOS but not COX-2 upon LPS stimulation and induces HO-1 in RAW 264.7 macrophages To examine the mechanism by which VYE reduces NO and cytokine production by LPS stimulation, we evaluated the effect of VYE on iNOS, COX-2, and HO1 expression in RAW 264.7 macrophages. The inhibitory effects of VYE on the protein and mRNA levels of iNOS, COX-2, and HO-1 were evaluated by Western blot analysis and real-time RT-PCR. As shown in Fig. 3a, VYE strongly reduced protein levels of iNOS. However, COX-2 protein expression was slightly repressed at concentrations of $10-150 \mu \mathrm{g} / \mathrm{mL}$. In addition, as shown in Fig. $3 \mathrm{~b}$, the HO-1 protein level was markedly augmented by VYE treatment. Consistent with this result, VYE treatment significantly repressed the expression of iNOS mRNA and induced that of HO-1 (Fig. 4a and c). By contrast, COX-2

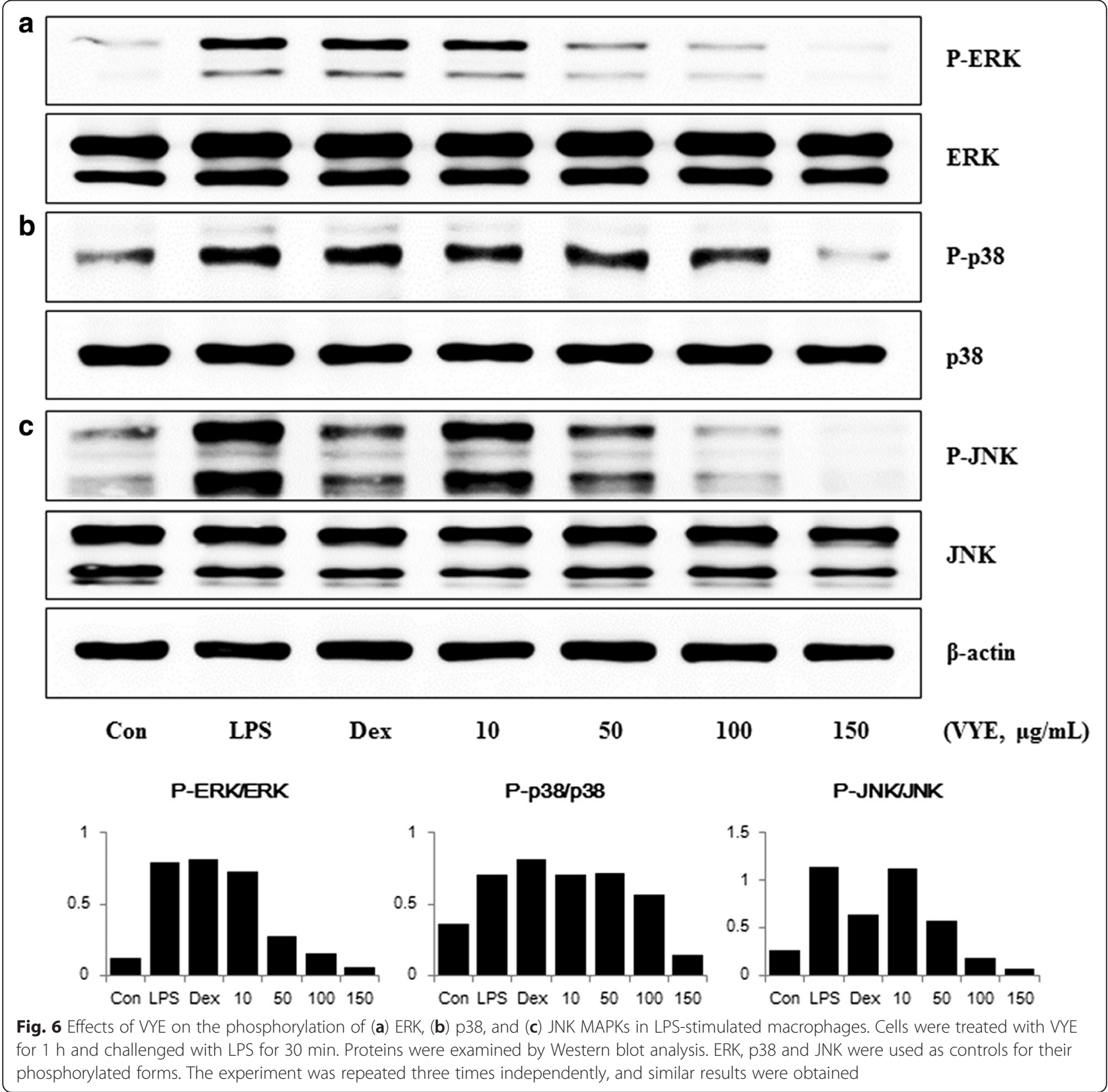


mRNA expression was repressed by VYE treatment, the opposite of the protein levels (Fig. 4b).

\section{Suppressive effects of VYE on activation of NF-kB signaling pathway in macrophages}

The NF-kB is closely related to inflammatory mediator production such as cytokines and iNOS. Therefore, we assessed the effect of VYE on the activation of NF-kB by analyzing nuclear translocation of p65 and $\mathrm{IkB} \alpha$ phosphorylation. As shown in Fig. 5a, VYE significantly inhibited nuclear translocation of NF-kB p65 by LPS stimulation at all concentrations $(10-150 \mu \mathrm{g} / \mathrm{mL})$. We also evaluated the effects of VYE on the phosphorylation and degradation of $I k B \alpha$ upon LPS stimulation. As shown in Fig. $5 \mathrm{~b}$, the activation of $\mathrm{IkB} \alpha$ through phosphorylation and degradation was reduced in a dose-dependently by VYE treatment. These results suggested that VYE inhibits translocation of NF-kB and phosphorylation, degradation of $\mathrm{IkB} \alpha$.

\section{VYE inhibits phosphorylation of MAPKs by LPS stimulation in RAW 264.7 cells}

The MAPK family members include ERK, p38, and JNK. MAPKs are activated by stimuli such as LPS, and play an essential role in the regulation of inflammatory mediator production. We examined whether activation of MAPKs is repressed by VYE treatment. As shown in Fig. $6 a$ and c, phosphorylation of ERK and JNK MAPK by LPS treatment was markedly decreased in a dosedependent manner. In addition, VYE only slightly affected p38 activity at concentrations of $10-100 \mu \mathrm{g} / \mathrm{mL}$, but strongly inhibited phosphorylation of p38 at the highest dose tested (150 $\mathrm{gg} / \mathrm{mL})$ (Fig. 6b).

\section{VYE inhibits cytokine production by LPS stimulation in mouse peritoneal macrophages}

First, we examined the anti-inflammatory activity of VYE on RAW 264.7 cell line. Next, we confirmed the inhibitory activity of VYE in mouse primary macrophages. We measured the levels of inflammatory cytokines-TNF- $\alpha$, IL-6, and IL-1 $\beta$. As shown in Fig. 7b, VYE significantly inhibited secretion of IL-6 in a dose-dependently. However, VYE at concentrations of $10-100 \mu \mathrm{g} / \mathrm{mL}$ only slightly inhibited or did not inhibit TNF- $\alpha$ and IL- $1 \beta$ secretion. In addition, $150 \mu \mathrm{g} / \mathrm{mL}$ VYE suppressed TNF- $\alpha$ and IL-1 $\beta$ production by peritoneal macrophages (Fig. $7 \mathrm{a}$ and $\mathrm{c}$ ). These results indicated that $150 \mu \mathrm{g} / \mathrm{mL}$ VYE effectively inhibited the inflammatory response in primary macrophage cells without toxicity (cell viability data not shown).

\section{Screening and analyzing bioactive components}

VYE, which has anti-inflammatory effects, was used for screening bioactive candidates that interact with RAW 264.7 cells. The compounds were screened and
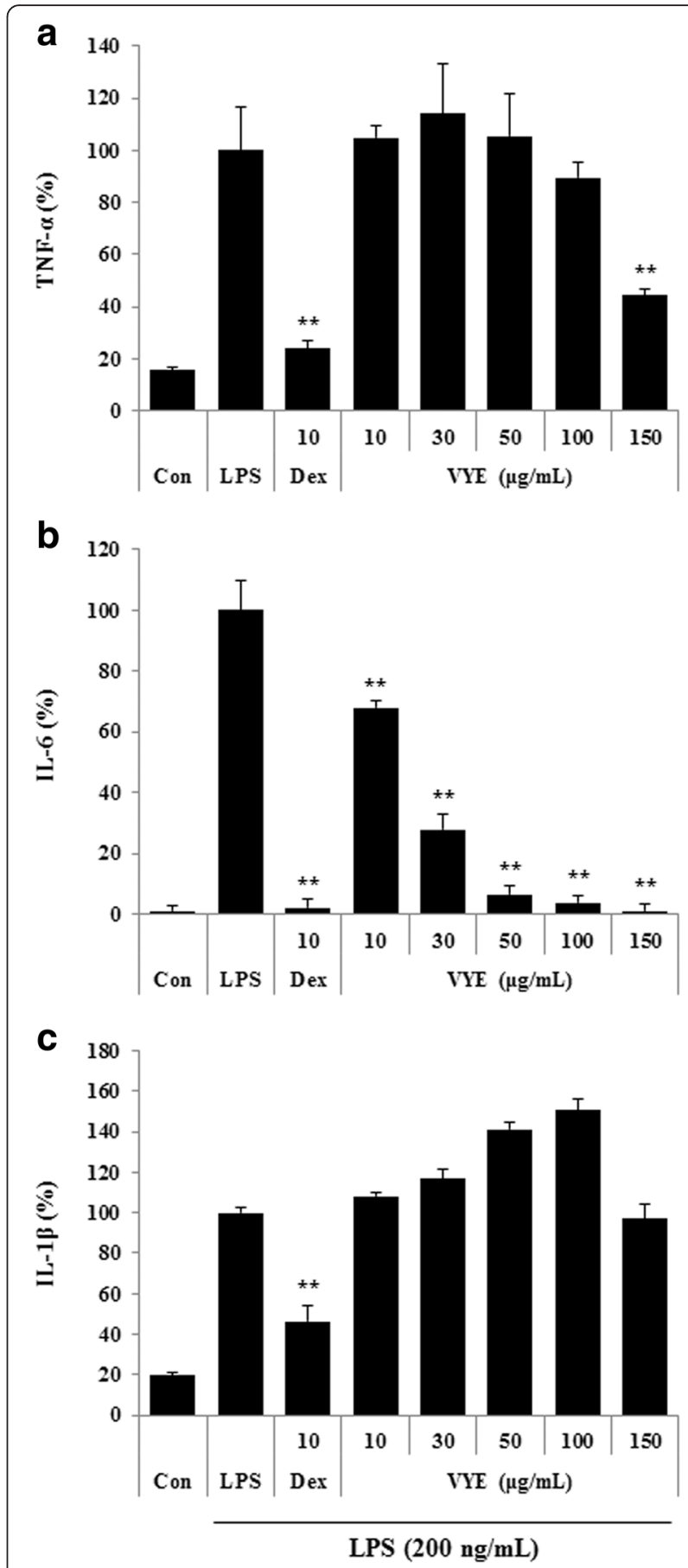

Fig. 7 Effect of VYE on LPS-induced (a) TNF-a, (b) IL-6, and (c) IL-1 $\beta$ cytokine production in mouse peritoneal macrophages. Mouse peritoneal macrophage cells were treated with VYE for $1 \mathrm{~h}$ prior to incubation with LPS for $24 \mathrm{~h}$. Cytokine levels in the culture supernatant were analyzed by ELISA. As a control, the cells were incubated with vehicle alone. Data represent the means \pm SE of three independent experiments. ${ }^{* *} p<0.001$ compared to the LPS-stimulated value 
analyzed using HPLC-DAD-QTOF MS. The UV chromatograms (monitored at $330 \mathrm{~nm}$ ) of extracts from VYE, blank control (desorption eluate of RAW 264.7 cells incubated without VYE), fourth wash eluate of cell extract, and desorption eluate of cells incubated with VYE are shown in Fig. 8. The chromatogram of VYE extract contained two major peaks at 271 and $338 \mathrm{~nm}$ (Fig. 8d). The chromatogram of desorption eluate of cell extract also showed these peaks. However, the chromatogram of the blank control and fourth wash eluate of cell extract did not. The mass chromatograms (monitored negative mode) of extracts from VYE, two major peaks were observed at $10.5 \mathrm{~min}(\mathrm{~m} / z \mathrm{563})$ and $11.8 \mathrm{~min}(\mathrm{~m} / z$ 533) (Fig. 9d). Each molecular ion peak at $\mathrm{m} / z 563$ and 533 was identified using the extracted ion chromatogram (EIC) mode (Fig. 10a and b). In Fig. 10a and b, the peak was detected only in the desorption eluate of cell extract. In other words, the interaction between components and cells was shown to be highly selective and strong.

\section{Isolation and identification of the bioactive candidates}

The two compounds of the $\mathrm{n}-\mathrm{BuOH}$ fraction of VYE were isolated from various open chromatography and TLC profiles (Fig. 11). The structures of two compounds were identified as isoschaftoside (1) $[26,27]$ and apigenin 6 , 8-di- $C$ - $\alpha$-L-arabinopyranoside (2) [27, 28] by spectroscopic analysis of the HPLC-DAD-MS, ${ }^{1} \mathrm{H}-\mathrm{NMR}$, and ${ }^{13} \mathrm{C}$-NMR (Figs. 12 and 13 )

\section{Compound 1}

The ${ }^{13} \mathrm{C}$-NMR spectrum of Fig. 12 showed one carbonyl carbon $[\delta 182.4], 15$ aromatic carbons, and typical carbon signals of a glucose moiety. These carbon signals were estimated to be flavonoid glycoside. The ${ }^{1} \mathrm{H}-\mathrm{NMR}$ spectrum of Fig. 12 showed ortho coupling between $\delta$ $6.92(2 \mathrm{H}, \mathrm{d}, \mathrm{J}=8.5 \mathrm{~Hz})$ and $\delta 8.03(2 \mathrm{H}, \mathrm{d}, \mathrm{J}=8.5 \mathrm{~Hz})$ and two anomeric protons [ $\delta 4.72$ and $\delta 4.76]$. The molecular formula was determined to be $\mathrm{C}_{26} \mathrm{H}_{28} \mathrm{O}_{14}$ based on the ESI-MS $\left(m / z 563.1441[\mathrm{M}-\mathrm{H}]^{-}\right)$. Consequently, the chemical structure of compound 1 was elucidated as apigenin 6 - $C$ - $\alpha$-L-arabinopyranosyl-8-C- $\beta$-D-glucopyranpside, which was named isoschaftoside.

\section{Compound 2}

The ${ }^{13} \mathrm{C}$-NMR spectrum of Fig. 13 contained one carbonyl carbon [ $\delta$ 182.3], 15 aromatic carbons, and typical carbon signals of the glucose moiety, similar to compound 1 . Therefore, the compound was estimated to be flavonoid glycoside. The ${ }^{1} \mathrm{H}$-NMR spectrum of Fig. 13 showed ortho coupling between $\delta 6.91(2 \mathrm{H}, \mathrm{d}, \mathrm{J}=$ $8.4 \mathrm{~Hz})$ and $\delta 8.02(2 \mathrm{H}, \mathrm{d}, \mathrm{J}=8.4 \mathrm{~Hz})$, and two anomeric protons $[\delta$ 4.70]. Its molecular ion peak was at $m / z$ $533.1363[\mathrm{M}-\mathrm{H}]^{-}$in the ESI-MS. The molecular formula was deduced as $\mathrm{C}_{25} \mathrm{H}_{26} \mathrm{O}_{13}$ on the basic ${ }^{1} \mathrm{H}-,{ }^{13} \mathrm{C}-\mathrm{NMR}$, and ESI-MS data. Thus, the chemical structure of compound 2 was determined to be apigenin $6,8-\mathrm{di}-\mathrm{C}-\alpha-\mathrm{L}-$ arabinopyranoside.

\section{Discussion}

VY is an important medicinal herb in traditional medicine and has been used to treat associated with inflammation-related diseases in Korea [1]. A previous study revealed that VY exerts anti-HIV effects [2], and another revealed anti-coagulant activity [3]. In addition, recent studies have shown the protective effect of VY on LPS-induced acute lung injury in mice [4].

In our present study, we evaluated the anti-inflammatory effect of VYE in LPS-induced RAW 264.7 cells and mouse

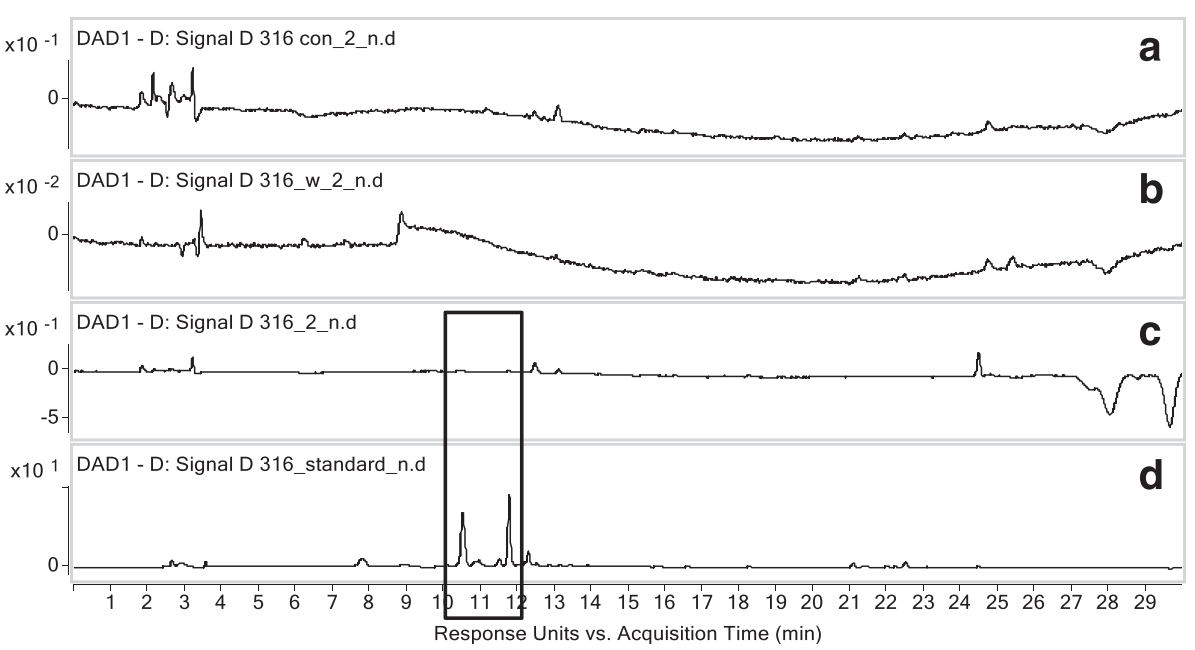

Fig. 8 UV chromatogram (330 nm). a Desorption eluate of RAW 264.7 cells incubated without VYE, b fourth wash eluate of cell extract, c desorption eluate of cells incubated with VYE, and $\mathbf{d}$ extract of VYE 


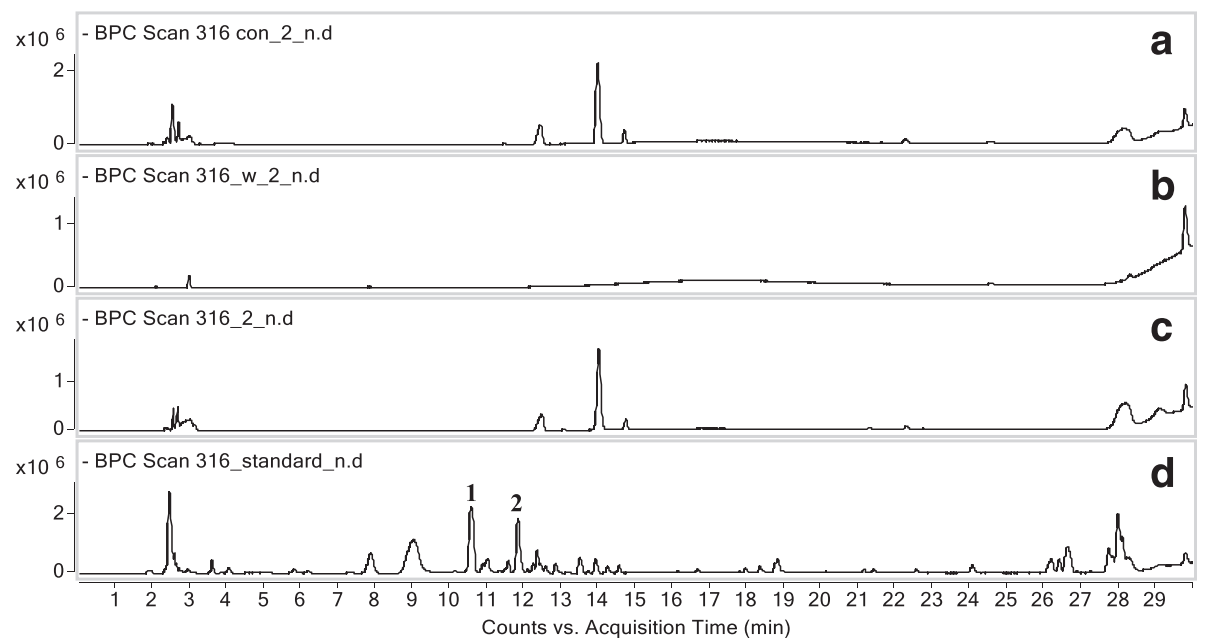

Fig. 9 Mass chromatogram (negative mode). a Desorption eluate of RAW 264.7 cells incubated without VYE, b fourth wash eluate of cell extract, c desorption eluate of cells incubated with VYE, and $\mathbf{d}$ extract of VYE

a

$\times 10^{3}-\operatorname{EIC}(563.0000)$ Scan 316 con_2_n.d

2-

x10 3 - EIC(563.0000) Scan 316_w_2_n.d

b

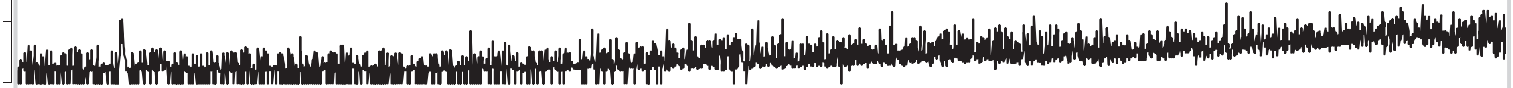

$\times 10^{3}-E I C(563.0000)$ Scan 316_2_n.d

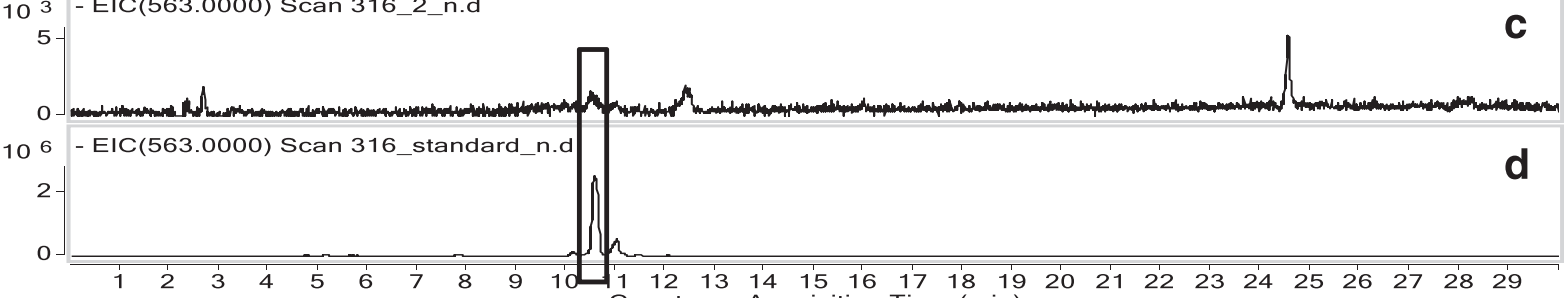
Counts vs. Acquisition Time (min)

b $\times 10^{3}-\operatorname{EIC}(533.0000)$ Scan 316 con_2_n.d

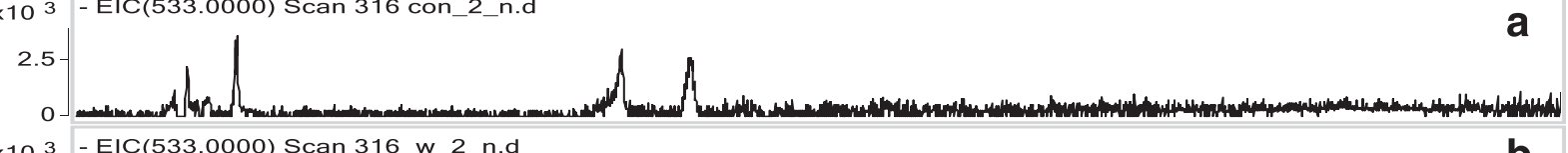

x10 3 - EIC(533.0000) Scan 316_w_2_n.d

b

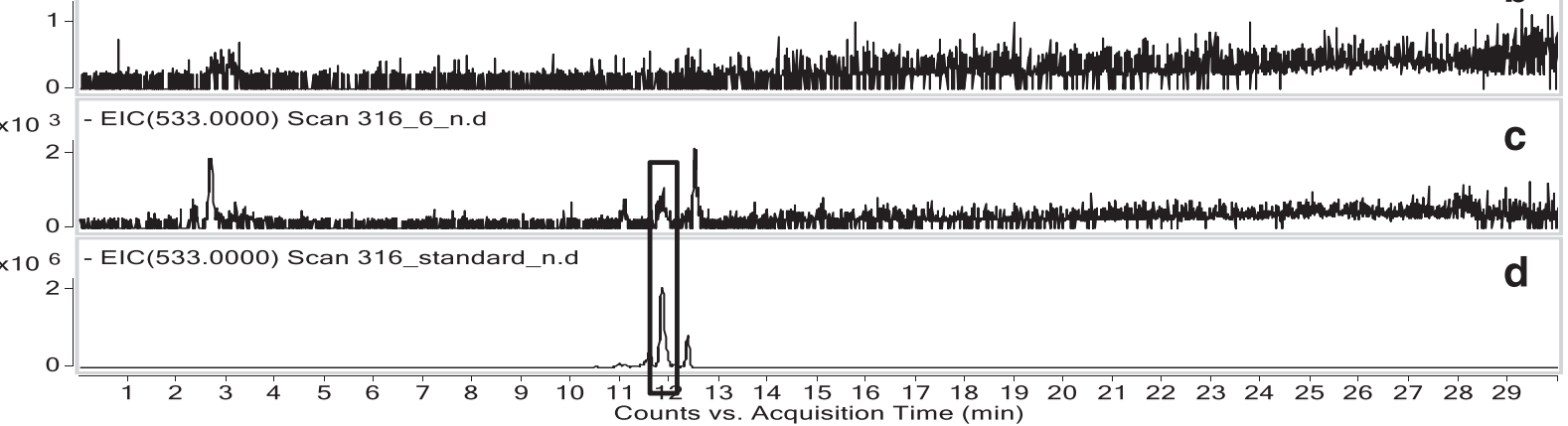

Fig. 10 (A) Extracted ion chromatogram (EIC) of VYE extract for 563 and (B) extracted ion chromatogram (EIC) of VYE extract for 533. (A) Desorption eluate of RAW 264.7 cells incubated without VYE, (B) fourth wash eluate of cell extract, (C) desorption eluate of cells incubated with VYE, and (D) extract of VYE 
Aerial parts of Viola yedoensis $(600 \mathrm{~g})$

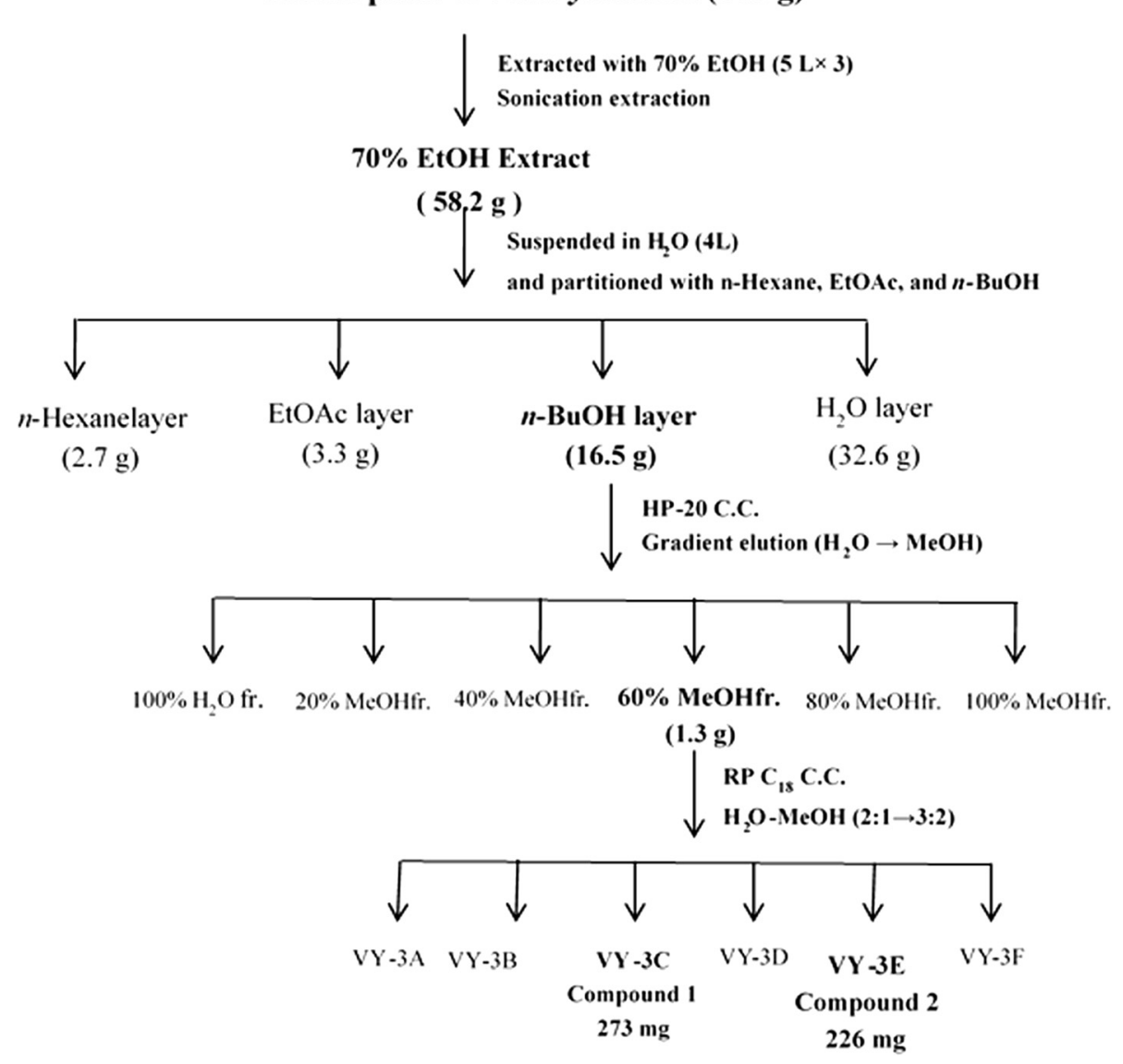

Fig. 11 Isolation from $V$. yedoensis

primary macrophages. First, we investigated that VYE treatment did not result in cytotoxicity to macrophages, did not affect cell viability at concentrations below $150 \mu \mathrm{g} /$ $\mathrm{mL}$. Overproduction of $\mathrm{NO}$ and iNOS is closely related to lots of inflammatory diseases $[29,30]$; thus, we examined the suppress effects of VYE on NO and iNOS production induced by LPS. We found that VYE strongly inhibited NO secretion and repressed expression of iNOS protein and mRNA levels, which is the synthesizing enzyme of $\mathrm{NO}$, in a concentration-dependent manner. These results indicate that the suppressive effect of VYE on iNOS expression conduce to the inhibition of $\mathrm{NO}$ secretion.

The expression of NO and iNOS was due to a direct influence on the induction of HO-1 [31], we further investigated the effect of VYE treatment on HO-1 expression. Thus, we determined the HO-1 protein and mRNA expression by VYE treatment absence of LPS. In our experiments, VYE exerts strongly induced HO-1 expression dose-dependently $(10-150 \mu \mathrm{g} / \mathrm{mL})$ in macrophage RAW 264.7, also the production of $\mathrm{HO}-1$ influenced the inhibitory activity of VYE on NO secretion and iNOS expression. This result about HO-1 expression suggests that the anti-inflammatory effects of VYE is influenced not only by a blockade of NF-kB and MAPK pathway activation but also by the induction of $\mathrm{HO}-1$.

VYE inhibited the secretion of inflammatory cytokines and expression of their mRNA genes, such as IL- 6 and IL- $1 \beta$. The transcription factor NF-kB is an important regulator of various genes involved in inflammatory responses [32]. After activation of NF-kB by LPS, IkB bound to NF-kB in cytoplasm becomes phosphorylated, leading to $\mathrm{p} 65$ translocation into the nucleus and phosphorylation of $\mathrm{IkB \alpha}$. Thus, we examined p65 levels in cytoplasmic and nuclear extracts by Western blotting. As a result, VYE reduced translocation and degradation of NF-kB p65, phosphorylation of $\mathrm{IkB} \alpha$ upon LPS stimulation in a dosedependent manner. These data are consistent with previous studies that indicated that NF-kB response elements are reveal in the promoters of the genes encoding iNOS and inflammatory cytokine [16, 33-35]. Since many anti-inflammatory drugs inhibit NF-kB activation, VYE extract could represent a novel anti-inflammatory agents. 


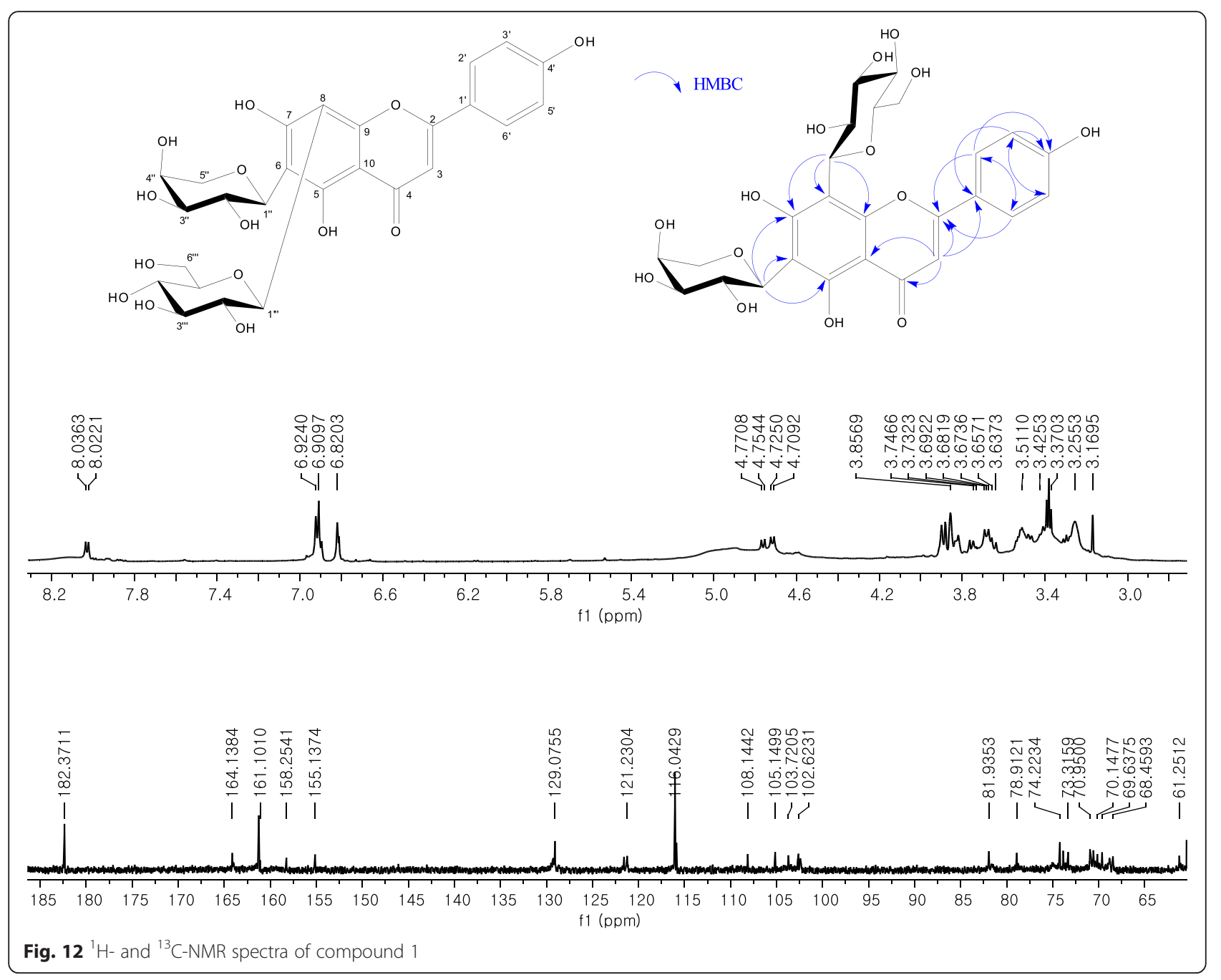

MAPKs activated by LPS are associated with production of inflammatory mediators such as iNOS expression in RAW 264.7 cells [36], we also investigated the inhibitory effect of VYE on MAPK phosphorylation. Phosphorylation of ERK and JNK MAPK were significantly inhibited, but had only a minor effect on the phosphorylation of p38 MAPK by VYE treatment. These results mean that the anti-inflammatory activity of VYE on MAPKs phosphorylation is directly involved in the inhibition of NF-kB activation and repression of inflammatory mediator production in macrophages. In this study, we examined whether VYE inhibits various inflammatory mechanisms, such as NF-kB, MAPK, and HO-1. We found that VYE shows strong inhibitory effects on various signaling pathways.

We further investigated the inhibitory activity of VYE on cytokine production in mouse peritoneal macrophages upon LPS stimulation to confirm its anti-inflammatory effect. Consistent with the results from cell lines, VYE significantly inhibited the production of IL- 6 cytokines in primary cells without exerting cytotoxicity. However, it did not inhibit TNF- $\alpha$ and IL- $1 \beta$ production, except at the highest concentration tested $(150 \mu \mathrm{g} / \mathrm{mL})$. These results suggest that VYE inhibits the inflammatory response not only in RAW 264.7 cells but also in primary cells.

In this study, we examined the anti-inflammatory activity and inhibitory mechanism of VYE. Numerous assays showed that VYE inhibited the production of inflammatory mediators including $\mathrm{NO}$ and proinflammatory cytokines such as TNF-a, IL-6 and IL- $1 \beta$, as well as activation of the NF-kB and MAPK signaling pathways. Moreover, expression of $\mathrm{HO}-1$ was strongly induced by VYE treatment. These results indicate that VYE has suppressive effects on inflammatory responses. Based on these results, we screened the potential bioactive components of VYE in macrophages by LC-MS and determined their chemical structure using HPLCDAD-MS, ${ }^{1} \mathrm{H}-\mathrm{NMR}$, and ${ }^{13} \mathrm{C}-\mathrm{NMR}$. We identified two major bioactive components that could interact with macrophages and investigated the structures of these 


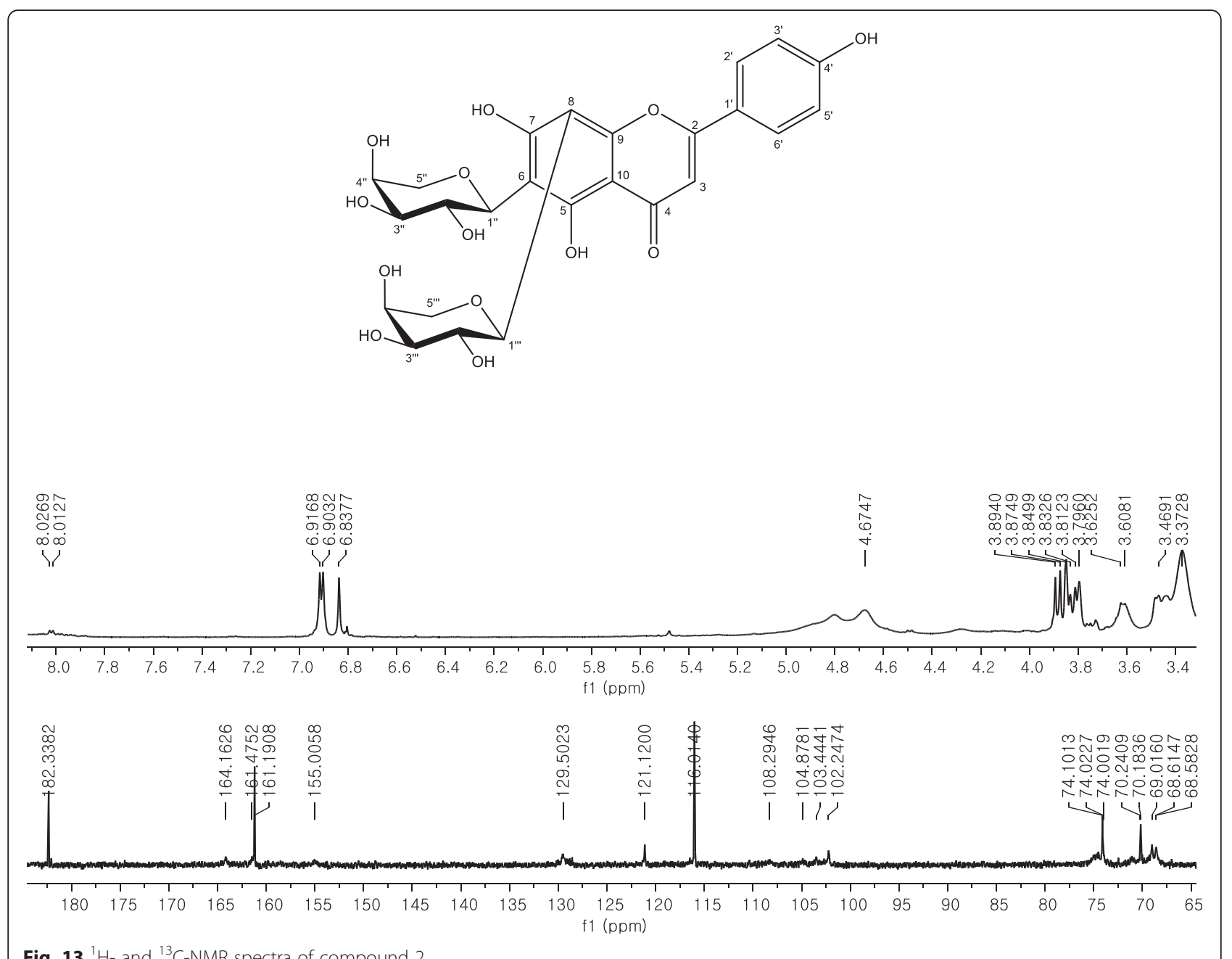

Fig. $13{ }^{1} \mathrm{H}$ - and ${ }^{13} \mathrm{C}-\mathrm{NMR}$ spectra of compound 2

compounds. The chemical structure of compound 1 was apigenin $\quad 6-C$ - $\alpha$-arabinopyranosyl-8- $C$ - $\beta$-D-glucopyranpside, called isoschaftoside. The chemical structure of compound 2 was apigenin 6,8 -di-C- $\alpha$-L-arabino-pyranoside.

In summary, we demonstrated the anti-inflammatory activity and inhibitory mechanism of VYE. We also identified two bioactive components that interact with macrophages and determined their structures. The role in inflammation of the two pure compounds warrants further studies.

\section{Conclusions}

In conclusion, the results of the present study demonstrated that VYE has strong inhibitory activity on production of inflammatory mediators including NO, inflammatory cytokines, and iNOS in LPS-stimulated RAW 264.7 cells. These effects are mediated by inhibiting NF-kB activation through $I \mathrm{kB} \alpha$ stabilization and blocking MAPK phosphorylation. In addition, induction of HO-1 expression by VYE involved in the inhibition of inflammatory mediators, and VYE inhibited the production of inflammatory cytokines in mouse primary macrophages. Furthermore, we screened two bioactive components and determined their chemical structure. These results indicate VYE to have potential as an antiinflammatory agent.

\section{Abbreviations}

ATCC, American Type Culture Collection; BSA, bovine serum albumin; CCK, cell counting kit; COX, cyclooxygenase; EIC, extracted ion chromatogram; ELISA, enzyme-linked immunesorbent assay; ERK, extracellular signal-regulated kinase; ESI, electrospray ionization; FBS, fetal bovine serum; $\mathrm{HO}$, heme oxygenase; HRP, horseradish peroxidase; IL, interleukin; iNOS, inducible nitric oxide synthase; IkBa, inhibitors of NF-kB alpha; JNK, Jun $\mathrm{NH}_{2}$-terminal kinase; LC-MS, high-performance liquid chromatography tandem mass spectrometry; LPS, lipopolysaccharide; MAPK, mitogen-activated protein kinase; NC, nitrocellulose; NF, nuclear factor; NO, nitric oxide; PBS, phosphate-buffered saline; RBC, red blood cell; RIPA, radio immunoprecipitation assay; RPMI, Roswell Park Memorial Institute; RT, room temperature; SDS-PAGE, sodium dodecyl sulfate-polyacrylamide gel electrophoresis; TNF, tumor necrosis factor; VY, Viola yedoensis; VYE, VY ethanol extract.

\section{Acknowledgements}

This work was supported by the grant K16281 awarded to Korea Institute of Oriental Medicine (KIOM) from Ministry of Education, Science and Technology 
(MEST), Korea and was supported by the National Research Foundation of Korea Grant funded by the Korean Government (NRF-2014R1A1A1003605).

\section{Availability of data and materials}

The datasets supporting the conclusions of this article are included within the article.

\section{Authors' contributions}

JYM developed the study design and critically revised the manuscript. KYL developed the study of cell extraction design and revised the manuscript. YHJ participated in the study design, carried out the experiments, analyzed the data and wrote the draft manuscript. YCO and WKC participated in the study design, carried out the experiments and analyzed the data. HS conducted the cell extraction experiments and analyzed the data. All authors read and approved the final manuscript.

\section{Competing interests}

The authors declare that they have no competing interests.

\section{Consent for publication}

Not applicable.

\section{Ethics approval and consent to participate}

Not applicable.

Received: 12 November 2015 Accepted: 25 May 2016

Published online: 14 June 2016

\section{References}

1. Editorial Committee of Chinese Pharmacopoeia. Pharmacopoeia of the People's Republic of China. Beijing: China Medical Science and Technology Press; 2010. p. 317

2. Wang CK, Colgrave ML, Gustafson KR, Ireland DC, Goransson U, Craik DJ. Anti-HIV cyclotides from the Chinese medicinal herb Viola yedoensis. J Nat Prod. 2008;71:47-52.

3. Zhou HY, Hong JL, Shu P, Ni YJ, Qin MJ. A new dicoumarin and anticoagulant activity from Viola yedoensis Makino. Fitoterapia. 2009;80:283-5.

4. Li W, Xie JY, Li H, Zhang YY, Cao J, Cheng ZH, et al. Viola yedoensis liposoluble fraction ameliorates lipopolysaccharide-induced acute lung injury in mice. Am J Chin Med. 2012;40:1007-18.

5. Kim JY, Park SJ, Yun KJ, Cho YW, Park HJ, Lee KT. Isoliquiritigenin isolated from the roots of Glycyrrhiza uralensis inhibits LPS-induced iNOS and COX-2 expression via the attenuation of NF-kB in RAW 264.7 macrophages. Eur J Pharmacol. 2008;584:175-84.

6. Lawrence T, Willoughby DA, Gilroy DW. Anti-inflammatory lipid mediators and insights into resolution of inflammation. Nat Rev Immunol. 2002;2:787-95.

7. Libby P. Inflammatory mechanisms: the molecular basis of inflammation and disease. Nutr Rev. 2007:65:S140-6.

8. Wang Y, Yu C, Pan Y, Li J, Zhang Y, Ye F, et al. A novel compound C12 inhibits inflammatory cytokine production and protects from inflammatory injury in vivo. PLoS One. 2011;6:e24377.

9. Borges MC, Vinolo MA, Crisma AR, Fock RA, Borelli P, Tirapegui J, et al. High-fat diet blunts activation of the nuclear factor-kappaB signaling pathway in lipopolysaccharide-stimulated peritoneal macrophages of Wistar rats. Nutrition. 2012;29:443-9.

10. Jin M, Suh SJ, Yang JH, Lu Y, Kim SJ, Kwon S, et al. Anti-inflammatory activity of bark of Dioscorea batatas DECNE through the inhibition of iNOS and COX-2 expressions in RAW264.7 cells via NF-kB and ERK1/2 inactivation. Food Chem Toxicol. 2012;48:3073-9.

11. Wu YH, Chuang SY, Hong WC, Lai YJ, Chang GJ, Pang JH. Berberine reduces leukocyte adhesion to LPS-stimulated endothelial cells and VCAM-1 expression both in vivo and in vitro. Int J Immunopathol Pharmacol. 2012;25:741-50.

12. Shao J, Liu T, Xie QR, Zhang T, Yu H, Wang B, et al. Adjudin attenuates lipopolysaccharide (LPS)- and ischemia-induced microglial activation. J Neuroimmunol. 2013;254:83-90.

13. de Martin R, Vanhove B, Cheng Q, Hofer E, Csizmadia V, Winkler H, et al. Cytokine-inducible expression in endothelial cells of an I kappa B alpha-like gene is regulated by NF kappa B. EMBO J. 1993;12:2773-9.

14. Barnes PJ, Karin M. Nuclear factor-kappaB: a pivotal transcription factor in chronic inflammatory diseases. N Engl J Med. 1997;336:1066-71.
15. Lappas M, Permezel M, Georgiou HM, Rice GE. Nuclear factor kappa B regulation of proinflammatory cytokines in human gestational tissues in vitro. Biol Reprod. 2002;67:668-73.

16. Baeuerle PA, Baltimore D. NF-kappa B: Ten years after. Cell. 1996;87:13-20.

17. Robinson MJ, Cobb MH. Mitogen-activated protein kinase pathways. Curr Opin Cell Biol. 1997:9:180-6.

18. Ryter SW, Alam J, Choi AM. Heme oxygenase-1/carbonmonoxide: frombasic science 498 to therapeutic applications. Physiol Rev. 2006;86:583-650.

19. Suh GY, Jin Y, Yi AK, Wang XM, Choi AM. CCAAT/enhancer-binding protein mediates carbon monoxide-induced suppression of cyclooxygenase-2. Am J Respir Cell Mol Biol. 2006:35:220-6.

20. Oh GS, Pae HO, Lee BS, Kim BN, Kim JM, Kim HR, Jeon SB, Jeon WK, Chae $\mathrm{HJ}$, Chung HT. Hydrogen sulfide inhibits nitric oxide production and nuclear factor-kB via hemeoxygenase-1 expression in RAW264.7 macrophages stimulated with lipopolysaccharide. Free Radic Biol Med. 2006:41:106-19.

21. He L, Wang S, Geng X. Coating and fusing cell membranes onto a silica surface and their chromatographic characteristics. Chromatographia. 2001; 54:71-6.

22. Luo H, Chen L, Li Z, Ding Z, Xu X. Frontal immunoaffinity chromatography with mass spectrometric detection: a method for finding active compounds from traditional Chinese herbs. Anal Chem. 2003;75:3994-8.

23. Fu Y, Liu B, Liu J, Liu Z, Liang D, Li F, et al. Geniposide, from Gardenia jasminoides Ellis, inhibits the inflammatory response in the primary mouse macrophages and mouse models. Int Immunopharmacol. 2012;14:792-8.

24. Choi HJ, Kang OH, Park PS, Chae HS, Oh YC, Lee YS, et al. Mume Fructus water extract inhibits pro-inflammatory mediators in lipopolysaccharidestimulated macrophages. J Med Food. 2007;10:460-6.

25. Wang QS, Xiang Y, Cui YL, Lin KM, Zhang XF. Dietary blue pigments derived from genipin, attenuate inflammation by inhibiting LPS-induced iNOS and COX-2 expression via the NF-kB inactivation. PLoS One. 2012;7:e34122.

26. Österdahl BG. Chemical studies on bryophytes. 22. Flavonoid C-glycosides of Mnium undulatum. Acta Chem Scand. 1979;33:400-4.

27. Xie C, Veitch NC, Houghton PJ, Simmonds MS. Flavone C-glycosides from Violayedoensis MAKINO. Chem Pharm Bull (Tokyo). 2003;51:1204-7.

28. Markham KR, Mues R, Stoll M, Zinsmeister HD. NMR spectra of flavone di-Cglycosides from Apometzgeria pubescens and the detection of rotational isomerism in 8-C-hexosylflavones. Z Naturforsch C. 1987:42:1039-42.

29. Guzik TJ, Korbut R, Adamek-Guzik T. Nitric oxide and superoxide in inflammation and immune regulation. J Physiol Pharmacol. 2003:54:469-87.

30. Southan GJ, Szabo C. Selective pharmacological inhibition of distinct nitric oxide synthase isoforms. Biochem Pharmacol. 1996;51:383-94.

31. Ashino T, Yamanaka R, Yamamoto M, Shimokawa H, Sekikawa K, Iwakura $Y$, et al. Negative feedback regulation of lipopolysaccharide-induced inducible nitric oxide synthase gene expression by heme oxygenase-1 induction in macrophages. Mol Immunol. 2008;45:2106-15.

32. Grilli M, Chiu JJ, Lenardo MJ. NF-kappa B and Rel: participants in a multiform transcriptional regulatory system. Int Rev Cytol. 1993;143:1-62.

33. Ahn KS, Noh EJ, Zhao HL, Jung SH, Kang SS, Kim YS. Inhibition of inducible nitric oxide synthase and cyclooxygenase II by Platycodon grandiflorum saponins via suppression of nuclear factor-kappaB activation in RAW 264.7 cells. Life Sci. 2005;76:2315-28.

34. Chen Y, Yang L, Lee TJ. Oroxylin A inhibition of lipopolysaccharide-induced iNOS and COX-2 gene expression via suppression of nuclear factor-kappaB activation. Biochem Pharmacol. 2000;59:1445-57.

35. Kim YM, Lee BS, Yi KY, Paik SG. Upstream NF-kappaB site is required for the maximal expression of mouse inducible nitric oxide synthase gene in interferon-gamma plus lipopolysaccharide-induced RAW 264.7 macrophages. Biochem Biophys Res Commun. 1997;236:655-60

36. Caivano M. Role of MAP kinase cascades in inducing arginine transporters and nitric oxide synthetase in RAW 264.7 macrophages. FEBS Lett. 1999;429: 249-53. 